\title{
Effects of Arsenic on Nutrient Accumulation and Distribution in Selected Ornamental Plants
}

\author{
Stewart T. Reed ${ }^{*}$, Tomas Ayala-Silva1, Christopher B. Dunn'1, Garry G. Gordon ${ }^{2}$ \\ ${ }^{1}$ USDA, Agricultural Research Service, Subtropical Horticulture Research Station, Miami, FL, USA \\ ${ }^{2}$ Department of Homeland Security, U.S. Customs and Border Protection, Miami Cargo Clearance Center, \\ Miami, FL, USA \\ Email: "stewart.reed@ars.usda.gov
}

Received 14 August 2015; accepted 25 December 2015; published 29 December 2015

Copyright (C) 2015 by authors and Scientific Research Publishing Inc.

This work is licensed under the Creative Commons Attribution International License (CC BY).

http://creativecommons.org/licenses/by/4.0/

(c) (i) Open Access

\section{Abstract}

In Miami, Florida, $95 \%$ of residential and 33\% commercial soils exceed the Florida Department of Environmental Protection goals for cleanup of arsenic contamination. Ornamental plants have not been fully investigated as a mechanism for phytoremediation of low level As contaminated soil. This study evaluates nutrient uptake by ornamental plants grown in a hydroponic system containing concentrations of $0,10,20,30,40,50$ or $70 \mathrm{uM}$ As $\left(0.0,0.75,1.5,3.0,3.75,5.25 \mathrm{mg} \cdot \mathrm{L}^{-1} \mathrm{As}\right.$, respectively). Uptake of $\mathrm{Ca}, \mathrm{K}, \mathrm{Mg}$ and Mo was likely influenced by the toxic effect of As on root functions. Arsenic had little effect on $\mathrm{Ca}, \mathrm{K}$ and $\mathrm{Mg}$ transportation to the shoot at any but the highest As exposure rate. Tissue $P$ concentration was similar to or higher than that found in controls and As competition with $P$ uptake occurred at $70 \mathrm{uM}$ As only. Tissue sulfur initially increased then subsequently decreased at $70 \mathrm{uM}$ As where uptake could no longer supply enough $S$ for both detoxification and normal metabolic needs. The effect of As on plant B was likely a result of membrane leakage and overall tissue damage leading to a reduction in transpiration. Arsenic induced Fe deficiency was likely the primary cause of chlorosis; however, As induced reduction in $\mathrm{Zn}$, Mn or Mg contributed to chlorosis. Copper use in cellular functions was very efficient; nevertheless, $\mathrm{Cu}$ deficiency was one of the initial effects of As toxicity. Differences in mineral uptake reflect the plant's attempt to detoxify As (i.e. increase in $S$ for S-containing As chelators), mitigate damage to the cell (i.e. Ca to repair leaky menbranes) or continue cellular functions through alternative pathways (i.e. Fe superoxide dismutases to replace the function of $\mathrm{Cu} / \mathrm{ZnSOD}$ ).

\section{Keywords}

Arsenic, Micronutrients, Secondary Nutrients, Iris, Marigold, Sunflower, Switchgrass

\footnotetext{
${ }^{*}$ Corresponding author.
}

How to cite this paper: Reed, S.T., Ayala-Silva, T., Dunn, C.B. and Gordon, G.G. (2015) Effects of Arsenic on Nutrient Accumulation and Distribution in Selected Ornamental Plants. Agricultural Sciences, 6, 1513-1531. 


\section{Introduction}

Arsenic-based rodenticides, herbicides, insecticides and irrigation with water high in As have resulted in As contamination on and around turf-farms, orchards, greenhouses, golf courses and residential lawns and gardens [1]-[3]. An average As concentration (AC) of $13.7 \mathrm{mg} \cdot \mathrm{kg}^{-1}$ was found in the fine clay fraction of 14 South Florida golf courses associated with high AC in groundwater [4]. Urban soils from Gainesville and Miami, Florida, have a range of 0.21 to $660 \mathrm{mg} \mathrm{As} \mathrm{kg}{ }^{-1}$ soil [5]. The Florida Department of Environmental Protection goals for cleanup of residential and industrial soils are 0.8 and $3.7 \mathrm{mg} \mathrm{As} \mathrm{kg}^{-1}$ soil, respectively. In Miami 95\% of soils sampled exceeded the Florida residential goal and 33\% exceeded the commercial goal. Soil contaminated with As levels above regulatory goals is a problem for people living in South Florida.

Arsenic is not essential for plants [6] and has no known metabolic function. Plant species vary in their tolerance to As [7] with toxicity threshold levels ranging from 5 to $100 \mathrm{mg} \mathrm{As} \mathrm{kg}^{-1}$ dry weight for most plants [8]. At low concentrations the oxidized form of As, arsenate, can act as an analogue of phosphate in which they share the same transport pathway [3] [9]. Arsenic may compete with P for uptake by high-affinity phosphate transporters in root cells [10]-[12]. Reduced As, arsenite, is likely taken up by aquaporin channels in plant roots [13]. Once arsenate is taken up by a root cells, a small amount may be transported to the xylem but the majority is reduced to arsenite [3]. Arsenite is either exported back into soil, transported in the xylem to stem and leaves, or complexed with an organic compound for storage in a vacuole. Arsenic non-hyperaccumulators tend to store most of the arsenite in the root with little transported to stem or leaf tissue. In rice (Oryza sativa) [14] [15], cucumber (Cucumis sativus) [16], Brassica juncea [17], tomato (Solanum lycopersicum) [18], Spartina patens and Spartina alterniflora [19], As is reduced to arsenite in the root with only a small portion transported to the shoot. In contrast, plants that accumulate As will translocate a large portion of it to the shoot. The As hyperaccumulator Pterisvittata translocated 8x more As from root to shoot than the non-hyperaccumulator P. tremula [20] and $2.8 \mathrm{x}$ more than $P$. ensiformis [21].

The effect of As on micronutrient allocation between roots and shoot is in part a function of the concentration of soil As and the plant species sensitivity to As [22]. In addition, adsorption by roots, translocation, plant tissue in question, growth stage, and metabolic interactions with other elements will influence the distribution of micronutrients in plants. Arsenic toxicity to root membranes can limit transport of elements to shoot tissue [23] [24]. For example, As damage in tomato roots reduced transpiration and thus reduced B concentration in stem tissue at fruiting [24]. Calculations of leaf-to-root concentration ratios in bean plants at a late vegetative stage showed lower $\mathrm{Cu}, \mathrm{Fe}$ and $\mathrm{Mn}$ concentrations with higher non-lethal As content in the growing media [25]. In tomato, higher non-lethal As resulted in lower $\mathrm{Mn}$ and higher $\mathrm{Zn}$ concentrations [22]. These differences were attributed to As induced interactions between various ions during uptake and translocation. For example, P-Cu interactions [26] [27] were believed to be influenced by As acting as an analog to P in metabolic reactions.

Arsenic in plant tissue rarely reaches levels toxic to humans because of its high toxicity to plants. Allocation between different plant tissue generally results in the lowest AC in fruit [22] [28]. The same As distribution should hold true for other reproductive parts.

Ornamental plants have not been fully investigated as a mechanism for phytoremediation of low level As contaminated soil. Ornamentals can partially offset the cost of contaminated land taken out of production through production of cut flowers and other marketable commodities. In addition, these plants can provide an aesthetic quality to buildings located on contaminated sites. A study was conducted to evaluate nutrient uptake by ornamental plants grown in a hydroponic system containing As. This report describes micronutrient distribution between root and shoot tissue in several ornamental plants.

\section{Materials and Methods}

\subsection{Plant Species}

Methods were previously described in [29]. The plants used in this study were iris (Iris savannarum), switchgrass (Panicum virgatum), Tithonia rotundiflora, Coreopsis lanceolata, sunflower (Helianthus annuus), and marigold (Tagetes erecta). A 25\% perlite, 37\% pine bark, 8\% sand, 30\% coir potting mixture was used for all plants except iris. Ten $\mathrm{cm}$ iris rhizomes, collected from a single plant were set in rockwool to help maintain rhizome orientation during ebb and flow cycles in the hydroponic system. Switchgrass seed was evenly sowed in $28 \times 53 \mathrm{~cm}$ trays. Once plants reached $10 \mathrm{~cm}$ in height, 30,18-cm sections of turf were cutout and placed into 
26-cm diameter pots (3.8 L). Switchgrass was trimmed to a uniform $15 \mathrm{~cm}$ height before treatments began. Tithonia, sunflower and marigold seedlings with at least two fully developed leaves, and iris and coreopsis plants, $10 \mathrm{~cm}$ tall with $\geq 3$ leaves, were placed in 26 - $\mathrm{cm}$ pots. The study was conducted over three different time periods with two plant species growing during each period. Dates for each time period are given in Table 1.

\subsection{Hydroponic System}

Six ebb-and-flow type hydroponic plant maintenance systems were used for the study. Each system contained a $208 \mathrm{~L}$ reservoir tank filled with $132 \mathrm{~L}$ water. Each tank was connected to 12, 3.8-L pots. A timer allowed the system to cycle between $30 \mathrm{~min}$. wet and $4 \mathrm{hr}$. drain periods, beginning at 8 A.M., ending at 4 P.M. followed by a $12 \mathrm{hr}$. drain period. A modified Hoagland solution was used to supply plant nutrients. Nutrients were added in the form of concentrated stock solutions before tanks were brought to their final volume. Final nutrient concentrations in each tank were $2.0 \mathrm{mM} \mathrm{Ca}\left(\mathrm{NO}_{3}\right)_{2}, 3 \mathrm{mM} \mathrm{KNO}_{3}, 1.0 \mathrm{mM} \mathrm{MgSO} \mathrm{M}_{4}, 0.25 \mathrm{mM} \mathrm{Ca}\left(\mathrm{H}_{2} \mathrm{PO}_{4}\right)_{2}, 12.5 \mathrm{uM}$ $\mathrm{H}_{3} \mathrm{BO}_{3}, 1.0 \mathrm{uM} \mathrm{MnSO}, 1.0 \mathrm{uM} \mathrm{ZnSO}_{4}, 0.25 \mathrm{uM} \mathrm{CuSO}_{4}, 0.2 \mathrm{uM}\left(\mathrm{NH}_{4}\right)_{6} \mathrm{Mo}_{7} \mathrm{O}_{24}$, and 10 uM Fe-EDDHA. Tap water used to mix nutrient solutions averaged $0.0028 \mathrm{mg} \cdot \mathrm{L}^{-1}$ As $(0.448 \mathrm{mg}$ per reservoir tank). Plants were acclimated to hydroponic feeding for a minimum of one week before beginning As treatments.

An As solution concentration of 2 - $8 \mathrm{uM}$ equates to a soil AC of $700-3000 \mathrm{mg} \cdot \mathrm{kg}^{-1}$ [30]. Based on this and the levels of contaminated urban soils reported above, a range of 10 - $70 \mathrm{uM}$ As solution concentration was selected to cover the range of low level As contamination found in south Florida's urban soils. Enough $\mathrm{Na}_{2} \mathrm{HAsO}_{4}$, dissolved in $1.0 \mathrm{~L}$ water, was added to different reservoirs to make a final tank concentration of $0,10,20,30,40$, 50 or $70 \mathrm{uM} \mathrm{As}\left(0.0,0.75,1.5,3.0,3.75,5.25 \mathrm{mg} \cdot \mathrm{L}^{-1}\right.$ As, respectively). Reservoir $\mathrm{pH}$ was adjusted daily to $\mathrm{pH}$ 6.5 with either $\mathrm{NaOH}$ or $\mathrm{H}_{2} \mathrm{SO}_{4}$. Nutrient and As solutions were replaced weekly. Plants were maintained in hydroponic solution until flowering.

\subsection{Sample Analysis}

Shoot and root tissue were harvested separately. Roots were washed with a gentle spray to remove debris, agitated in a pool of water then washed a second time. Shoot and root tissue were oven dried at $45^{\circ} \mathrm{C}$ until there was no longer a weight change with additional drying and the dry weights recorded. Dried tissue was stored for analysis. Approximately $0.25 \mathrm{~g}$ of oven dried plant tissue was placed in $100-\mathrm{mL}$ digestion tubes. Ten $\mathrm{mL} \mathrm{HNO}_{3}$ was added and samples digested in a microwave digestion system for 15 min to reach $200^{\circ} \mathrm{C}$ then kept at this temperature for an additional $15 \mathrm{~min}$. Digests were diluted to $100 \mathrm{~mL}$ and stored at $4^{\circ} \mathrm{C}$ prior to analysis. Element concentrations were determined by inductively coupled plasma-optical emission spectrometry with an iCAP 6300 Duo View (ThermoFisher Scientific, West Palm Beach, Florida). Data were analyzed and concentrations determined using ThermoFisher Scientific iCAP 6300 iTEVA software. A translocation factor (TF) was calculated as:

$$
\mathrm{TF}=\text { shoot As/root As in } \mathrm{mg} \text { As } \mathrm{kg}^{-1} \text { plant dry weight }
$$

for each species and each treatment.

\subsection{Statistical Analysis}

Each plant species was analyzed separately. The data represent means calculated from six replicated pots for

Table 1. Planting, initiation of arsenic treatments and harvest dates for six plant species: iris, switchgrass (Panicum virgatum), Tithonia rotundiflora, Coreopsis lanceolata, sunflower (Helianthus annuus) and marigold (Tagetes erecta).

\begin{tabular}{|c|c|c|c|}
\hline Species & Planting & Treatment & Harvest \\
\hline Iris savannarum & 21-Dec-09 & 10-Mar-10 & 13-May-10 \\
\hline Switchgrass (Panicum virgatum) & 21-Dec-09 & 10-Mar-10 & 13-May-10 \\
\hline Tithonia rotundiflora & $6-O c t-10$ & 20-Oct-10 & 16-Nov-10 \\
\hline Coreopsis lanceolata & $6-O c t-10$ & 20-Oct-10 & 23-Nov-10 \\
\hline Sunflower (Helianthus annuus) & 1-Feb-11 & 16-Feb-11 & 22-Mar-11 \\
\hline Marigold (Tagetes erecta) & 1-Feb-11 & 16-Feb-11 & 22-Mar-11 \\
\hline
\end{tabular}


each As treatment. Analysis of variance was performed using the Proc Mixed procedure of Statistical Analysis System [31]. Tukey adjusted least square means were used for comparison at $P<0.05$ unless stated otherwise. Arithmetic means were used to calculate translocation factors.

\section{Results}

\subsection{Dry Weight}

Both coreopsis root and shoot dry weights declined with increasing solution AC (Figure 1(a)). Coreopsis 0.0 As control treatment produced at mean dry weight of $6.9 \mathrm{~g}$ with a shoot-to-root ratio of 2.52. Healthy roots could support 2.5x their weight in above ground dry matter. At $0.75 \mathrm{mg} \mathrm{As} \mathrm{L}^{-1}$ solution there was a $32 \%$ reduction in dry weight; reductions for 2.25 , and $5.25 \mathrm{mg} \mathrm{As} \mathrm{L}^{-1}$ were $65 \%$ and $84 \%$, respectively. A significant drop in dry weight began at $2.25 \mathrm{mg} \mathrm{As} \mathrm{L}^{-1}$; however, up to that point the allocation of dry matter between shoot and root tissue (shoot-to-root ratio) remained in a range from 2.5 and 2.3. As plants became smaller the loss in dry weight was equally shared by shoot and root tissue. A concentration of $5.25 \mathrm{mg} \mathrm{As} \mathrm{L}^{-1}$ resulted in a drop in shoot-to root ration to 1.5. At this level of exposure, roots damaged by As had dropped below a critical level and a proportional shoot weight similar to that produced in the control could no longer be maintained.

Tithonia produced a mean dry weight in the control of $34.2 \mathrm{~g}$ (Figure 1(b)). Addition of as little as $0.75 \mathrm{mg}$ As $\mathrm{L}^{-1}$ resulted in a $79 \%$ reduction in dry weight. In contrast to coreopsis, the dry weight shoot-to-root ratio for tithonia change very little with an increase in solution As, ranging from 1.11 to 0.98 decreasing steadily from 0.0 to $3.75 \mathrm{mg}$ As $\mathrm{L}^{-1}$, respectively.

In iris, a solution AC of $0.75 \mathrm{mg} \cdot \mathrm{L}^{-1}$ reduced total plant dry weight accumulation to $50 \%$ of the control (Figure 1(c)). However, higher ACs up to $5.25 \mathrm{mg} \cdot \mathrm{L}^{-1}$, increased plant dry weight. This was true for both root and shoot tissue. Whole plant dry weight increased over controls by $1.8 \%$ and $2.2 \%$ with solution ACs of 3.0 and $5.25 \mathrm{mg}$ as $\mathrm{L}^{-1}$, respectively. The initial decrease in dry weight at low AC and subsequent increase in dry weight at higher ACs may result from complex interactions with other elements ( $\mathrm{Fe}$ and $\mathrm{Mn}$ ) during uptake and translocation. These interactions at low AC might inhibit growth but all defensive mechanisms may not be fully mobilized until solution AC increases. This will be discussed in more detail below. In addition to the reduction in dry weight, the shoot-to-root ratio slightly decreased from 3.0 in the 0.0 As control to 2.5 in the $0.75 \mathrm{mg}$ As $\mathrm{L}^{-1}$ solution treatment. As dry weight increased with higher solution AC, shoot-to-root ratio returned to levels near those found in control plants, 2.8 and 3.0 for the 3.0 and $5.25 \mathrm{mg} \mathrm{As} \mathrm{L}^{-1}$ solution treatments, respectively.

Marigold's dry weight was statistically similar in all treatments for both shoot and root tissue (Figure 1(d)). Shoot-to-root ratios were higher in As treatments than that in the control. Sunflower performed similar to marigold in that there were no differences in dry weight between treatments (Figure 1(e)). Sunflower dry weights tended to decline with increasing solution AC. Shoot-to-root ratios were higher in plant treated with 0.75 and $3.75 \mathrm{mg} \mathrm{As} \mathrm{L}^{-1}$ solution As. Switchgrass dry weight decreased with increasing solution AC (Figure 1(f)). The drop in shoot dry weight was greater than that in roots resulting in a constant drop in shoot-to-root ratio with an increase in solution AC.

\subsection{Arsenic Content}

Arsenic accumulated by coreopsis plants tended to remain in root tissue (Figure 2(a)). As solution As increased,

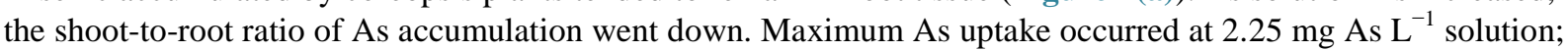
above that level shoot As began to decline faster than root As. Switchgrass also accumulated As mostly in root tissue and the shoot-to-root ratio decreased with increasing solution As (Figure 2(f)). Very little As was taken up by iris plants (Figure 2(c)). More of the As taken up by iris was translocated to the shoot in all but the $3.0 \mathrm{mg}$ As $\mathrm{L}^{-1}$ solution treatment. A high sensitivity in tithonia to As, as seen in the reduction in dry weight at 0.75 $\mathrm{mg} \cdot \mathrm{L}^{-1}$ solution concentration resulted in low As accumulation in plant tissue (Figure 2(b)). The shoot-to-root

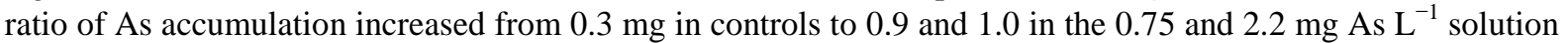
treatments. At $3.75 \mathrm{mg} \cdot \mathrm{L}^{-1}$ plant uptake dropped to $0.4 \mathrm{mg}$ As. Although there were no statistical differences in marigold root As, uptake tended to increase with increasing solution concentration. Marigold shoot As was higher than that in controls, however, less As was partitioned to shoot tissue with increasing solution concentration (Figure 2(d)). Sunflower root and shoot As content increased with increasing solution AC (Figure 2(e)). The shoot-to-root ratio for As was $0.9,0.7,0.8$ and 0.8 in the $0.0,0.75,3.75$ and $5.25 \mathrm{mg} \cdot \mathrm{L}^{-1}$ treatments, respectively. 

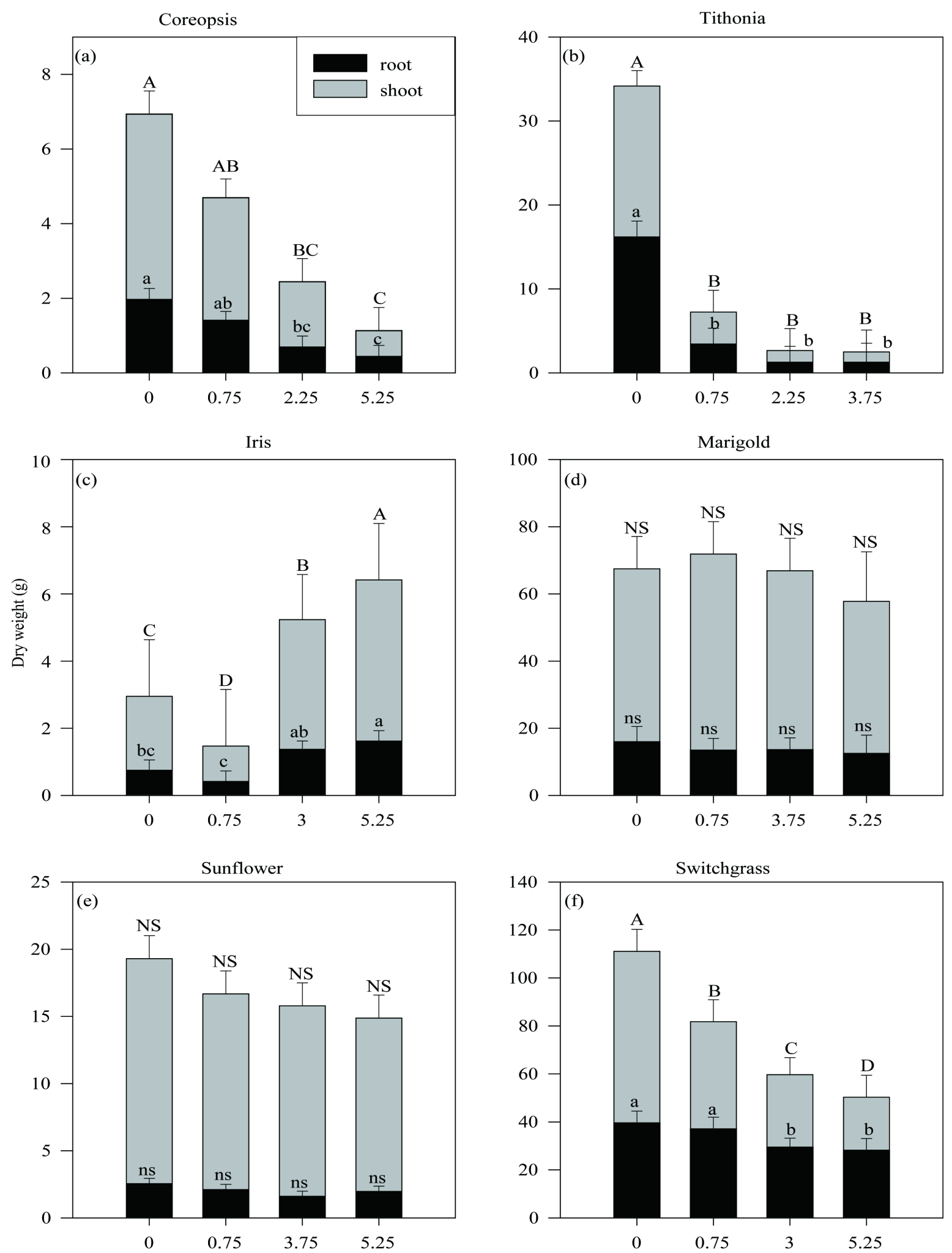

Solution As concentration $\left(\mathrm{mg} \cdot \mathrm{L}^{-1}\right)$

Figure 1. Effects of As concentration on mean root (black bar) and shoot (grey bar) tissue dry weights (g). Bar sections with the same letter are not significantly different at $P=0.05$; capital letters designate shoot and lower case letters root weights. ns = not significantly different. 

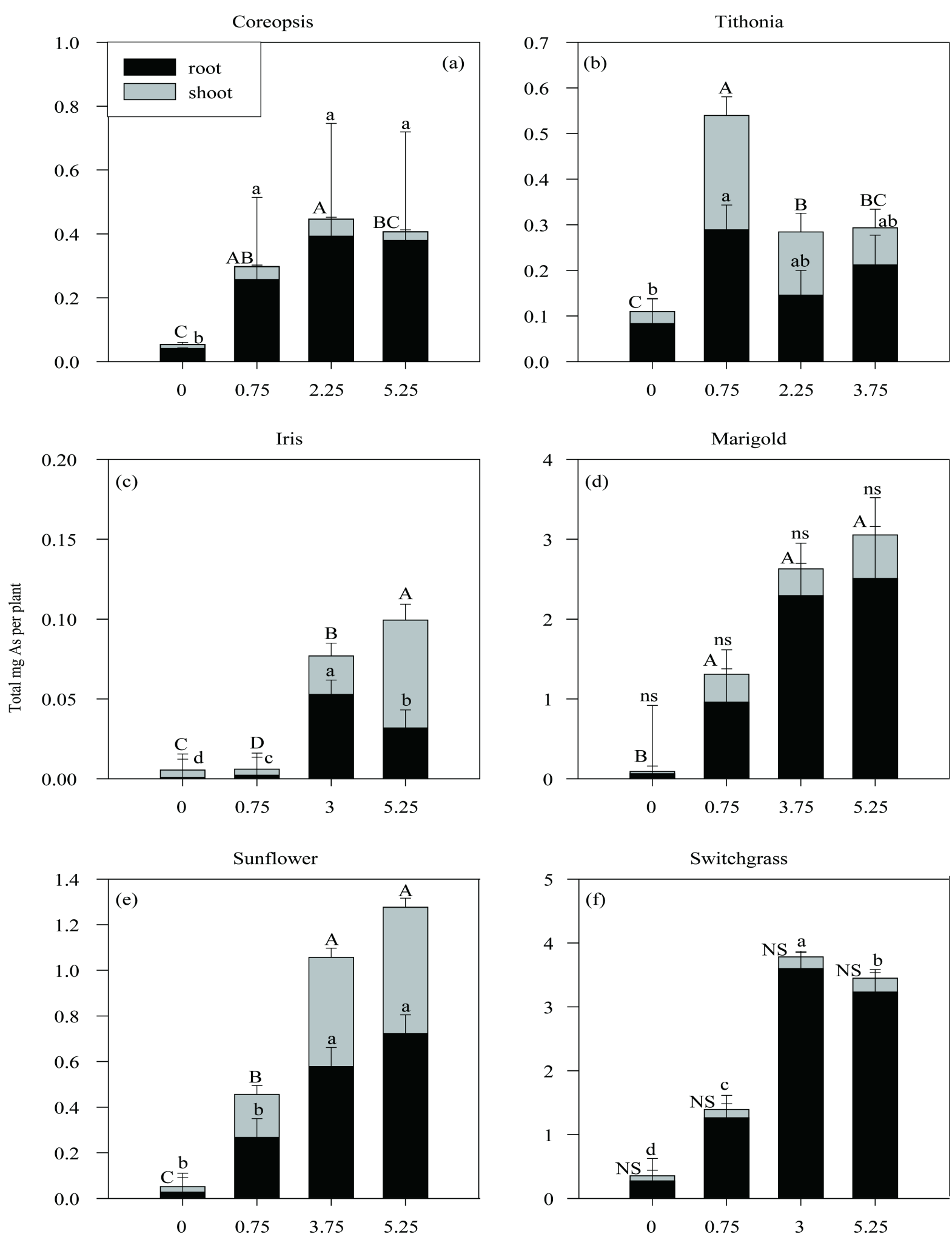

Solution As concentration $\left(\mathrm{mg} \cdot \mathrm{L}^{-1}\right)$

Figure 2. Effect of solution As concentration on root (black bar) and shoot (grey bar) tissue arsenic content in accumulated mg. Bar sections with the same letter are not significantly different at $P=0.05$; capital letters designate shoot and lower case letters root weights. $\mathrm{ns}=$ not significantly different. 


\subsection{Plant as Concentration}

The AC in coreopsis root and shoot tissue increased with increasing hydroponic solution AC (Figure 3(a)). Considering the continuous decrease in dry weight combined with an increase in As uptake to a solution con-

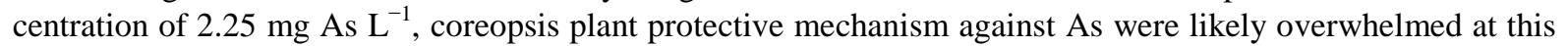
point. A higher AC was found in coreopsis root than shoot tissue. Maximum tithonia tissue AC was reached at $2.25 \mathrm{mg} \mathrm{As} \mathrm{L}^{-1}$ (Figure 3(b)). Tithonia maintained a high shoot AC in all treatments.
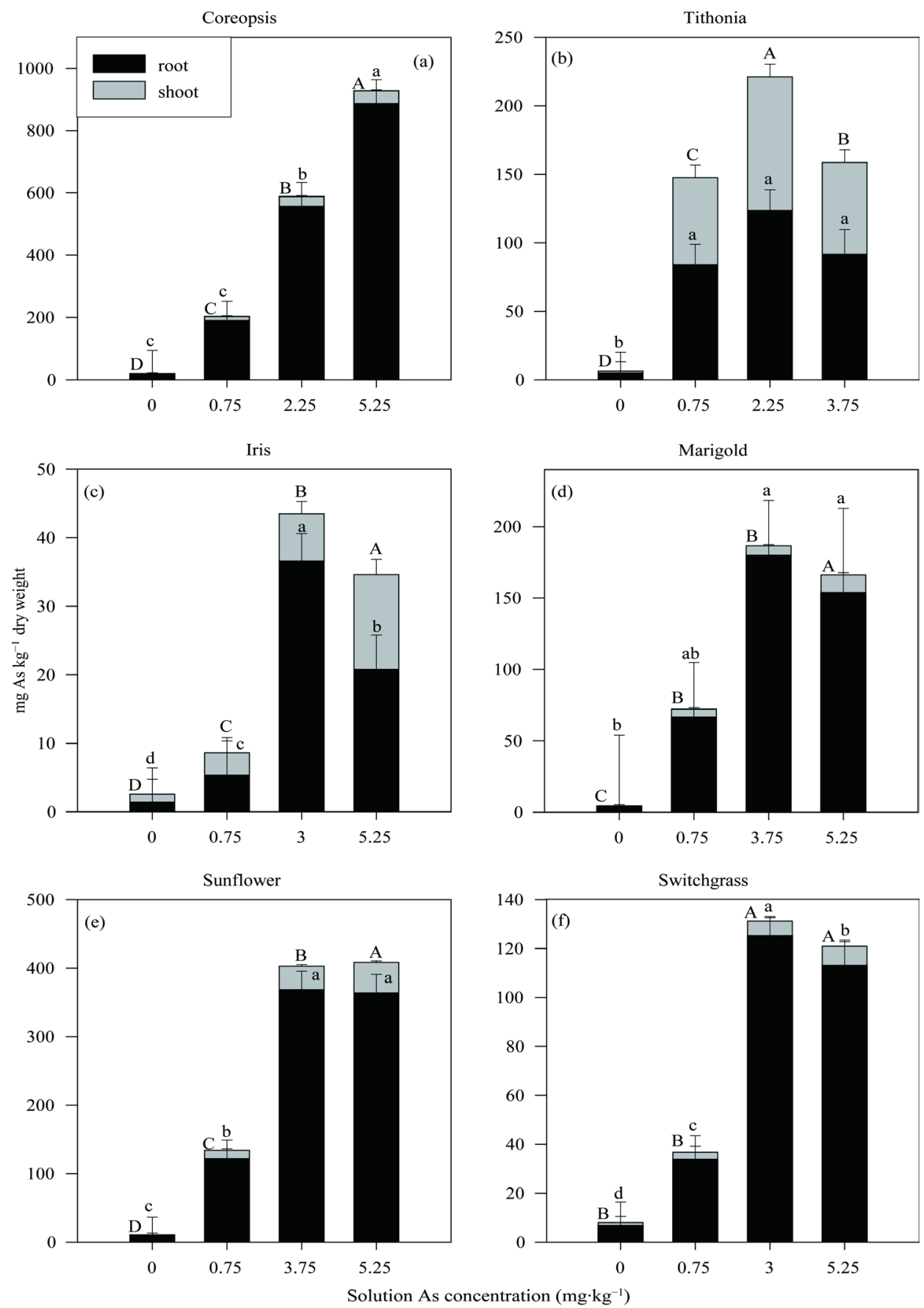

Figure 3. Effect of solution As concentration on root (black bar) and shoot (grey bar) tissue As concentration (mg As $\mathrm{kg}^{-1}$ dry weight). Bar sections with the same letter are not significantly different at $P=$ 0.05; capital letters designate shoot and lower case letters root weights. ns = not significantly different. 
Iris whole plant AC increased at $0.75 \mathrm{mg} \cdot \mathrm{L}^{-1}$ solution concentration due to an initial drop in plant dry weight (Figure 3(c)). Subsequent increases in tissue AC were due to increased As uptake. Shoot AC increased with increasing solution As. At $5.25 \mathrm{mg}$ As $\mathrm{L}^{-1}$ solution plant uptake was highest; however, AC declined due to a relatively small increase in root dry weight accompanied by greater transport of As to shoot tissue.

Marigold whole plant tissue AC peaked at $3.75 \mathrm{mg} \mathrm{As} \mathrm{L}^{-1}$ solution (Figure 3(d)). At a hydroponic solution concentration of $5.25 \mathrm{mg} \mathrm{As}^{-1}$, shoot tissue AC dropped off due to a lower dry weight produced by that treat-

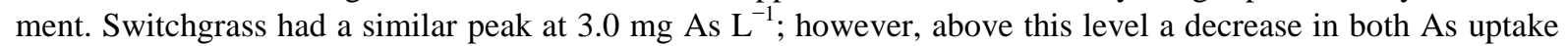
and dry weight reduced tissue AC (Figure 3(f)). Sunflower AC peaked at $3.75 \mathrm{mg} \cdot \mathrm{L}^{-1}$ solution As; however, there was a slight increase in shoot AC with an increase in solution As to $5.25 \mathrm{mg} \cdot \mathrm{L}^{-1}$ (Figure 3(e)).

\subsection{Plant Element Uptake}

In coreopsis all elements trended to a decrease in root content with an increase in solution As (Table 2). Differ-

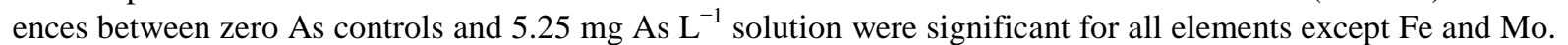
For $\mathrm{Ca}, \mathrm{Cu}, \mathrm{K}$ and $\mathrm{P}$ significant differences appeared at $0.75 \mathrm{mg} \cdot \mathrm{L}^{-1}$ solution As. A similar decrease in shoot element content with increasing solution As was found in shoot tissue. Shoot tissue had higher element content than root tissue for all elements except Fe and Mo (Table 2).

Table 2. The effect of solution As concentration on element distribution between shoot and root tissue (mg per plant).

\begin{tabular}{|c|c|c|c|c|c|c|c|c|c|c|c|}
\hline $\begin{array}{l}\text { Solution As } \\
\text { concentration } \\
\left(\mathrm{mg} \mathrm{As} \mathrm{L}^{-1}\right)\end{array}$ & B & $\mathrm{Ca}$ & $\mathrm{Cu}$ & $\mathrm{Fe}$ & $\mathrm{K}$ & $\mathrm{Mg}$ & $\mathrm{Mn}$ & Mo & $\mathrm{P}$ & $\mathrm{S}$ & $\mathrm{Zn}$ \\
\hline \multicolumn{12}{|c|}{ Coreopsis lanceolata } \\
\hline \multicolumn{12}{|c|}{ Shoot } \\
\hline 0.00 & $0.2082 \mathrm{a}^{\mathrm{f}}$ & 80.15 a & 0.003889 a & 0.3323 а & 329.02 a & $32.10 \mathrm{a}$ & 0.2232 a & 0.0028 a & $27.2460 \mathrm{a}$ & $13.57 \mathrm{ab}$ & $0.1305 \mathrm{a}$ \\
\hline 0.75 & $0.1337 \mathrm{ab}$ & $54.68 \mathrm{ab}$ & $0.000372 \mathrm{~b}$ & $0.1645 \mathrm{~b}$ & $242.69 \mathrm{ab}$ & $17.32 \mathrm{~b}$ & $0.2254 \mathrm{a}$ & 0.0027 a & $17.4340 \mathrm{~b}$ & 18.59 a & $0.1515 \mathrm{a}$ \\
\hline 2.25 & 0.0758 bc & 29.85 bc & $0.000103 \mathrm{~b}$ & $0.1044 \mathrm{~b}$ & 110.13 bc & 11.48 bc & $0.1318 a b$ & $0.0015 \mathrm{ab}$ & $7.7110 \mathrm{c}$ & 5.82 bc & $0.0432 \mathrm{~b}$ \\
\hline 5.25 & 0.0263 c & 13.88 c & $0.000038 \mathrm{~b}$ & $0.0401 \mathrm{~b}$ & $36.74 \mathrm{c}$ & $5.31 \mathrm{c}$ & $0.0610 \mathrm{~b}$ & $0.0011 \mathrm{~b}$ & $2.5680 \mathrm{c}$ & $2.36 \mathrm{c}$ & $0.0162 \mathrm{~b}$ \\
\hline \multicolumn{12}{|c|}{ Root } \\
\hline 0.00 & 0.0237 a & $13.63 \mathrm{a}$ & $0.0005490 \mathrm{a}$ & $0.5380 \mathrm{~ns}$ & $82.68 \mathrm{a}$ & $4.88 \mathrm{a}$ & $0.0307 \mathrm{a}$ & $0.0041 \mathrm{~ns}$ & $11.51 \mathrm{a}$ & $8.12 \mathrm{a}$ & $0.0549 \mathrm{a}$ \\
\hline 0.75 & 0.0229 a & $6.72 \mathrm{~b}$ & $0.0000208 \mathrm{~b}$ & $0.4329 \mathrm{~ns}$ & $52.20 \mathrm{~b}$ & $3.05 \mathrm{ab}$ & 0.0318 a & $0.0029 \mathrm{~ns}$ & $6.93 \mathrm{~b}$ & $7.27 \mathrm{ab}$ & $0.0401 \mathrm{a}$ \\
\hline 2.25 & $0.0115 \mathrm{~b}$ & $3.50 \mathrm{~b}$ & $0.0000040 \mathrm{~b}$ & $0.3321 \mathrm{~ns}$ & 35.33 bc & $2.09 \mathrm{~b}$ & $0.0164 \mathrm{ab}$ & $0.0024 \mathrm{~ns}$ & $4.81 \mathrm{bc}$ & $4.20 \mathrm{ab}$ & $0.0207 \mathrm{~b}$ \\
\hline 5.25 & $0.0086 \mathrm{~b}$ & $2.68 \mathrm{~b}$ & $0.0000012 \mathrm{~b}$ & $0.1078 \mathrm{~ns}$ & $24.36 \mathrm{c}$ & $1.20 \mathrm{~b}$ & $0.0078 \mathrm{~b}$ & $0.0010 \mathrm{~ns}$ & $2.48 \mathrm{c}$ & $2.99 \mathrm{~b}$ & $0.0171 \mathrm{~b}$ \\
\hline \multicolumn{12}{|c|}{ Iris (Iris savannarum) } \\
\hline \multicolumn{12}{|c|}{ Shoot } \\
\hline 0.00 & $0.1029 a b$ & $21.17 \mathrm{ab}$ & $0.00664 \mathrm{~ns}$ & 0.1629 bc & $149.9 \mathrm{~ns}$ & $8.69 \mathrm{ab}$ & $0.0249 \mathrm{~ns}$ & $0.0017 \mathrm{~b}$ & $15.6690 \mathrm{~ns}$ & $6.74 \mathrm{~b}$ & $0.0509 \mathrm{~ns}$ \\
\hline 0.75 & $0.0437 \mathrm{~b}$ & $8.75 \mathrm{~b}$ & $0.01087 \mathrm{~ns}$ & $0.0780 \mathrm{c}$ & $70.2 \mathrm{~ns}$ & $3.71 \mathrm{~b}$ & $0.0068 \mathrm{~ns}$ & $0.0010 \mathrm{~b}$ & $7.1220 \mathrm{~ns}$ & $4.92 \mathrm{~b}$ & $0.0236 \mathrm{~ns}$ \\
\hline 3.00 & $0.1656 \mathrm{ab}$ & $31.54 \mathrm{ab}$ & $0.00100 \mathrm{~ns}$ & $0.2906 \mathrm{ab}$ & $252.0 \mathrm{~ns}$ & $13.23 \mathrm{ab}$ & $0.0350 \mathrm{~ns}$ & 0.0053 a & $24.5440 \mathrm{~ns}$ & $15.52 \mathrm{ab}$ & $0.0846 \mathrm{~ns}$ \\
\hline 5.25 & $0.2170 \mathrm{a}$ & 39.92 a & $0.00044 \mathrm{~ns}$ & 0.4377 a & $303.2 \mathrm{~ns}$ & $17.31 \mathrm{a}$ & $0.0378 \mathrm{~ns}$ & $0.0033 \mathrm{ab}$ & $29.4390 \mathrm{~ns}$ & 20.48 a & $0.0870 \mathrm{~ns}$ \\
\hline \multicolumn{12}{|c|}{ Root } \\
\hline 0.00 & $0.0190 \mathrm{~b}$ & $2.60 \mathrm{~b}$ & 0.00123 a & $0.0703 \mathrm{~ns}$ & $15.97 \mathrm{~b}$ & $1.34 \mathrm{~b}$ & $0.0058 \mathrm{~ns}$ & $0.0006 \mathrm{~b}$ & $2.9821 \mathrm{~b}$ & $1.24 \mathrm{c}$ & $0.0236 \mathrm{ab}$ \\
\hline 0.75 & $0.0137 \mathrm{~b}$ & $2.37 \mathrm{~b}$ & $0.00021 \mathrm{ab}$ & $0.0413 \mathrm{~ns}$ & $8.58 \mathrm{~b}$ & $0.87 \mathrm{~b}$ & $0.0049 \mathrm{~ns}$ & $0.0005 \mathrm{~b}$ & $1.7966 \mathrm{~b}$ & 1.32 c & $0.0181 \mathrm{~b}$ \\
\hline 3.00 & 0.0398 a & $8.76 \mathrm{a}$ & $0.00007 \mathrm{~b}$ & $1.3009 \mathrm{~ns}$ & 38.18 a & $4.00 \mathrm{a}$ & $0.0428 \mathrm{~ns}$ & $0.0012 \mathrm{a}$ & $6.5892 \mathrm{a}$ & $4.67 \mathrm{~b}$ & $0.0392 \mathrm{ab}$ \\
\hline 5.25 & $0.0552 \mathrm{a}$ & $11.72 \mathrm{a}$ & $0.00051 \mathrm{ab}$ & $1.7084 \mathrm{~ns}$ & $52.87 \mathrm{a}$ & $4.85 \mathrm{a}$ & $0.0534 \mathrm{~ns}$ & 0.0013 a & $7.2494 \mathrm{a}$ & $5.84 \mathrm{a}$ & 0.0459 a \\
\hline
\end{tabular}




\section{Continued}

\begin{tabular}{|c|c|c|c|c|c|c|c|c|c|c|c|}
\hline \multicolumn{12}{|c|}{ Marigold (Tagetes erecta) } \\
\hline \multicolumn{12}{|c|}{ Shoot } \\
\hline 0.00 & $1.6424 \mathrm{~ns}$ & 759.4 ns & $0.8375 \mathrm{~ns}$ & $3.11 \mathrm{~ns}$ & $2003.1 \mathrm{~ns}$ & $126.57 \mathrm{~ns}$ & $2.8894 \mathrm{~ns}$ & $0.0200 \mathrm{~ns}$ & $309.8600 \mathrm{~ns}$ & $144.31 \mathrm{~ns}$ & $6.698 \mathrm{~ns}$ \\
\hline 0.75 & $2.0378 \mathrm{~ns}$ & $745.2 \mathrm{~ns}$ & $0.0323 \mathrm{~ns}$ & $5.31 \mathrm{~ns}$ & $1907.5 \mathrm{~ns}$ & $132.78 \mathrm{~ns}$ & $3.0097 \mathrm{~ns}$ & $0.0274 \mathrm{~ns}$ & $317.7700 \mathrm{~ns}$ & $186.95 \mathrm{~ns}$ & $5.911 \mathrm{~ns}$ \\
\hline 3.75 & $1.7653 \mathrm{~ns}$ & $754.8 \mathrm{~ns}$ & $0.0274 \mathrm{~ns}$ & $3.57 \mathrm{~ns}$ & $1976.6 \mathrm{~ns}$ & $135.66 \mathrm{~ns}$ & $3.2861 \mathrm{~ns}$ & $0.0172 \mathrm{~ns}$ & $290.5600 \mathrm{~ns}$ & $165.78 \mathrm{~ns}$ & $4.838 \mathrm{~ns}$ \\
\hline 5.25 & $1.4036 \mathrm{~ns}$ & $856.5 \mathrm{~ns}$ & $0.0170 \mathrm{~ns}$ & $2.96 \mathrm{~ns}$ & $1725.1 \mathrm{~ns}$ & $122.55 \mathrm{~ns}$ & $3.3772 \mathrm{~ns}$ & $0.0235 \mathrm{~ns}$ & $317.2100 \mathrm{~ns}$ & $178.32 \mathrm{~ns}$ & $3.984 \mathrm{~ns}$ \\
\hline \multicolumn{12}{|c|}{ Root } \\
\hline 0.00 & $0.2842 \mathrm{~ns}$ & $133.38 \mathrm{~ns}$ & $0.0818 \mathrm{a}$ & $23.87 \mathrm{~ns}$ & $212.84 \mathrm{~ns}$ & $28.60 \mathrm{~ns}$ & $3.3070 \mathrm{~ns}$ & $0.0608 \mathrm{~ns}$ & $18.6710 \mathrm{~ns}$ & $49.65 \mathrm{~ns}$ & $2.4165 \mathrm{~ns}$ \\
\hline 0.75 & $0.2770 \mathrm{~ns}$ & 103.13 ns & $0.0045 \mathrm{~b}$ & $19.78 \mathrm{~ns}$ & $202.08 \mathrm{~ns}$ & $20.73 \mathrm{~ns}$ & $2.6458 \mathrm{~ns}$ & $0.0478 \mathrm{~ns}$ & $17.5780 \mathrm{~ns}$ & $40.26 \mathrm{~ns}$ & $2.3926 \mathrm{~ns}$ \\
\hline 3.75 & $0.2486 \mathrm{~ns}$ & $118.90 \mathrm{~ns}$ & $0.0020 \mathrm{~b}$ & $20.46 \mathrm{~ns}$ & $181.31 \mathrm{~ns}$ & $25.95 \mathrm{~ns}$ & $2.9634 \mathrm{~ns}$ & $0.0521 \mathrm{~ns}$ & $21.3600 \mathrm{~ns}$ & $60.16 \mathrm{~ns}$ & $2.8357 \mathrm{~ns}$ \\
\hline 5.25 & $0.2720 \mathrm{~ns}$ & $134.90 \mathrm{~ns}$ & $0.0040 \mathrm{~b}$ & $28.14 \mathrm{~ns}$ & $143.09 \mathrm{~ns}$ & $23.60 \mathrm{~ns}$ & $2.2950 \mathrm{~ns}$ & $0.0598 \mathrm{~ns}$ & $21.5990 \mathrm{~ns}$ & $45.70 \mathrm{~ns}$ & $1.9958 \mathrm{~ns}$ \\
\hline \multicolumn{12}{|c|}{ Sunflower (Helianthus annuus L.) } \\
\hline \multicolumn{12}{|c|}{ Shoot } \\
\hline 0.00 & $1.0808 \mathrm{~ns}$ & $242.93 \mathrm{~ns}$ & $0.1110 \mathrm{a}$ & $1.16 \mathrm{~ns}$ & $674.60 \mathrm{~ns}$ & $69.27 \mathrm{~ns}$ & $0.5007 \mathrm{~ns}$ & $0.0132 \mathrm{~ns}$ & $107.6400 \mathrm{~ns}$ & $60.23 \mathrm{~ns}$ & $1.2283 \mathrm{~ns}$ \\
\hline 0.75 & $1.2906 \mathrm{~ns}$ & $277.70 \mathrm{~ns}$ & $0.0082 \mathrm{~b}$ & $0.90 \mathrm{~ns}$ & $714.30 \mathrm{~ns}$ & $73.05 \mathrm{~ns}$ & $0.6209 \mathrm{~ns}$ & $0.0157 \mathrm{~ns}$ & $118.7900 \mathrm{~ns}$ & $89.90 \mathrm{~ns}$ & $1.7752 \mathrm{~ns}$ \\
\hline 3.75 & $1.0321 \mathrm{~ns}$ & $258.70 \mathrm{~ns}$ & $0.0018 \mathrm{~b}$ & $1.30 \mathrm{~ns}$ & $778.50 \mathrm{~ns}$ & $70.42 \mathrm{~ns}$ & $1.0815 \mathrm{~ns}$ & $0.0152 \mathrm{~ns}$ & $136.5300 \mathrm{~ns}$ & $85.31 \mathrm{~ns}$ & $1.7795 \mathrm{~ns}$ \\
\hline 5.25 & $0.8877 \mathrm{~ns}$ & $227.63 \mathrm{~ns}$ & $0.0017 \mathrm{~b}$ & $0.71 \mathrm{~ns}$ & $549.20 \mathrm{~ns}$ & $61.67 \mathrm{~ns}$ & $0.5687 \mathrm{~ns}$ & $0.0102 \mathrm{~ns}$ & $92.9500 \mathrm{~ns}$ & $59.40 \mathrm{~ns}$ & $1.0679 \mathrm{~ns}$ \\
\hline \multicolumn{12}{|c|}{ Root } \\
\hline 0.00 & $0.0483 \mathrm{~ns}$ & $17.22 \mathrm{~ns}$ & $0.004104 \mathrm{a}$ & $1.40 \mathrm{~ns}$ & $68.95 \mathrm{~ns}$ & $3.30 \mathrm{~ns}$ & $0.2974 \mathrm{~ns}$ & $0.0058 \mathrm{~ns}$ & $8.2870 \mathrm{~ns}$ & $10.20 \mathrm{a}$ & $0.2294 \mathrm{~ns}$ \\
\hline 0.75 & $0.0477 \mathrm{~ns}$ & $14.17 \mathrm{~ns}$ & $0.000306 \mathrm{~b}$ & $1.71 \mathrm{~ns}$ & $57.40 \mathrm{~ns}$ & $2.52 \mathrm{~ns}$ & $0.3581 \mathrm{~ns}$ & $0.0057 \mathrm{~ns}$ & $9.8070 \mathrm{~ns}$ & $6.65 \mathrm{ab}$ & $0.2076 \mathrm{~ns}$ \\
\hline 3.75 & $0.0289 \mathrm{~ns}$ & $10.00 \mathrm{~ns}$ & $0.000055 \mathrm{~b}$ & $0.72 \mathrm{~ns}$ & $46.34 \mathrm{~ns}$ & $2.04 \mathrm{~ns}$ & $0.1352 \mathrm{~ns}$ & $0.0035 \mathrm{~ns}$ & $8.1670 \mathrm{~ns}$ & $5.88 \mathrm{ab}$ & $0.2627 \mathrm{~ns}$ \\
\hline 5.25 & $0.0372 \mathrm{~ns}$ & $12.93 \mathrm{~ns}$ & $0.000087 \mathrm{~b}$ & $1.37 \mathrm{~ns}$ & $53.30 \mathrm{~ns}$ & $2.37 \mathrm{~ns}$ & $0.2587 \mathrm{~ns}$ & $0.0054 \mathrm{~ns}$ & $9.2220 \mathrm{~ns}$ & $4.11 \mathrm{~b}$ & $0.3129 \mathrm{~ns}$ \\
\hline \multicolumn{12}{|c|}{ Switchgrass (Panicum virgatum) } \\
\hline \multicolumn{12}{|c|}{ Shoot } \\
\hline 0.00 & 1.0028 a & 329.13 a & $0.1062 \mathrm{~ns}$ & $9.19 \mathrm{~ns}$ & 2394.40 a & 369.10 a & 0.9095 a & 0.0339 a & 390.0200 a & 138.68 a & 1.4759 a \\
\hline 0.75 & $0.6768 \mathrm{~b}$ & 224.37 b & $0.0192 \mathrm{~ns}$ & $3.33 \mathrm{~ns}$ & $1547.20 \mathrm{~b}$ & $247.72 \mathrm{~b}$ & 0.7926 a & $0.0194 \mathrm{~b}$ & $257.2100 \mathrm{~b}$ & 160.86 a & $0.9271 \mathrm{~b}$ \\
\hline 3.00 & $0.3997 \mathrm{bc}$ & 161.17 bc & $0.0050 \mathrm{~ns}$ & $2.30 \mathrm{~ns}$ & $999.20 \mathrm{c}$ & 167.31 c & 0.7596 a & $0.0166 \mathrm{~b}$ & $177.2200 \mathrm{bc}$ & $137.44 \mathrm{a}$ & $0.6454 \mathrm{~b}$ \\
\hline 5.25 & 0.2971 c & $96.47 \mathrm{c}$ & $0.0033 \mathrm{~ns}$ & $2.29 \mathrm{~ns}$ & $563.60 \mathrm{c}$ & $80.96 \mathrm{~d}$ & $0.3969 \mathrm{~b}$ & $0.0114 \mathrm{~b}$ & $107.1500 \mathrm{c}$ & $65.40 \mathrm{~b}$ & $0.3010 \mathrm{c}$ \\
\hline \multicolumn{12}{|c|}{ Root } \\
\hline 0.00 & $0.7386 \mathrm{~ns}$ & $692.2 \mathrm{~ns}$ & $0.0249 \mathrm{~ns}$ & $145.51 \mathrm{~ns}$ & 770.97 a & $244.15 \mathrm{~ns}$ & $4.2170 \mathrm{~ns}$ & $0.0407 \mathrm{ab}$ & $113.1300 \mathrm{a}$ & $73.73 \mathrm{~ns}$ & $1.0507 \mathrm{a}$ \\
\hline 0.75 & $0.6282 \mathrm{~ns}$ & $605.5 \mathrm{~ns}$ & $0.0122 \mathrm{~ns}$ & $124.72 \mathrm{~ns}$ & $566.68 \mathrm{~b}$ & $188.22 \mathrm{~ns}$ & $3.3480 \mathrm{~ns}$ & 0.0608 a & $113.2000 \mathrm{a}$ & $91.02 \mathrm{~ns}$ & $0.3889 \mathrm{~b}$ \\
\hline 3.00 & $0.4056 \mathrm{~ns}$ & $421.4 \mathrm{~ns}$ & $0.0007 \mathrm{~ns}$ & $74.70 \mathrm{~ns}$ & $549.71 \mathrm{~b}$ & $168.50 \mathrm{~ns}$ & $2.3100 \mathrm{~ns}$ & $0.0253 \mathrm{~b}$ & $93.1000 \mathrm{ab}$ & $84.98 \mathrm{~ns}$ & $0.4974 \mathrm{~b}$ \\
\hline 5.25 & $0.6113 \mathrm{~ns}$ & $498.9 \mathrm{~ns}$ & $0.0061 \mathrm{~ns}$ & $87.86 \mathrm{~ns}$ & 321.16 c & $127.35 \mathrm{~ns}$ & $2.5050 \mathrm{~ns}$ & $0.0421 \mathrm{ab}$ & $45.0500 \mathrm{~b}$ & $73.63 \mathrm{~ns}$ & $0.5357 \mathrm{~b}$ \\
\hline \multicolumn{12}{|c|}{ Tithonia rotundiflora } \\
\hline \multicolumn{12}{|c|}{ Shoot } \\
\hline 0.00 & $1.0084 \mathrm{a}$ & 448.7 a & 0.01919 a & $2.90 \mathrm{a}$ & 989.4 a & 145.95 a & 0.3776 a & $0.0150 \mathrm{a}$ & 225.0700 a & 61.90 a & 0.3676 a \\
\hline 0.75 & $0.2256 \mathrm{~b}$ & $97.4 \mathrm{~b}$ & $0.00012 \mathrm{~b}$ & $0.42 \mathrm{~b}$ & $156.7 \mathrm{~b}$ & $34.42 \mathrm{~b}$ & $0.1199 \mathrm{~b}$ & $0.0025 \mathrm{~b}$ & $55.6200 \mathrm{~b}$ & $22.34 \mathrm{~b}$ & $0.0961 \mathrm{~b}$ \\
\hline 2.25 & $0.0520 \mathrm{~b}$ & $17.6 \mathrm{~b}$ & $0.00002 \mathrm{~b}$ & $0.11 \mathrm{~b}$ & $37.2 \mathrm{~b}$ & $8.23 \mathrm{~b}$ & $0.0250 \mathrm{~b}$ & $0.0011 \mathrm{~b}$ & $7.9900 \mathrm{~b}$ & $4.32 \mathrm{~b}$ & $0.0148 \mathrm{~b}$ \\
\hline 3.75 & $0.0381 \mathrm{~b}$ & $15.0 \mathrm{~b}$ & $0.00002 \mathrm{~b}$ & $0.15 \mathrm{~b}$ & $31.2 \mathrm{~b}$ & $6.87 \mathrm{~b}$ & $0.0234 \mathrm{~b}$ & $0.0011 \mathrm{~b}$ & $7.3400 \mathrm{~b}$ & $4.64 \mathrm{~b}$ & $0.0082 \mathrm{~b}$ \\
\hline \multicolumn{12}{|c|}{ Root } \\
\hline 0.00 & 0.1788 a & 62.28 a & $0.02842 \mathrm{~ns}$ & $35.02 \mathrm{a}$ & 281.95 a & 19.86 a & $0.4611 \mathrm{a}$ & 0.2635 a & 25.5350 a & $21.22 \mathrm{a}$ & $0.3041 \mathrm{a}$ \\
\hline 0.75 & $0.0355 \mathrm{~b}$ & $10.03 \mathrm{~b}$ & $0.00015 \mathrm{~ns}$ & $1.98 \mathrm{~b}$ & $37.78 \mathrm{~b}$ & $2.70 \mathrm{~b}$ & $0.0870 \mathrm{~b}$ & $0.0097 \mathrm{~b}$ & $5.9890 \mathrm{~b}$ & $5.19 \mathrm{~b}$ & $0.0751 \mathrm{~b}$ \\
\hline 2.25 & $0.0109 \mathrm{~b}$ & $2.85 \mathrm{~b}$ & $0.00002 \mathrm{~ns}$ & $0.46 \mathrm{~b}$ & $6.03 \mathrm{~b}$ & $0.79 \mathrm{~b}$ & $0.0307 \mathrm{~b}$ & $0.0023 \mathrm{~b}$ & $1.4270 \mathrm{~b}$ & $0.95 \mathrm{~b}$ & $0.0121 \mathrm{c}$ \\
\hline 3.75 & $0.0070 \mathrm{~b}$ & $3.33 \mathrm{~b}$ & $0.00003 \mathrm{~ns}$ & $1.91 \mathrm{~b}$ & $11.25 \mathrm{~b}$ & $1.06 \mathrm{~b}$ & $0.0367 \mathrm{~b}$ & $0.0044 \mathrm{~b}$ & $1.9050 \mathrm{~b}$ & $1.98 \mathrm{~b}$ & 0.0193 c \\
\hline
\end{tabular}

${ }^{\mathrm{I}}$ Numbers in an individual column followed by the same letter are not significantly different at $P=0.05$; ns $=$ no significant difference. 
Due to a small amount of sample available from the tithonia $5.25 \mathrm{mg} \mathrm{As} \mathrm{L}^{-1}$ treatment, the highest As treatment level reported in Table 2 for tithonia is from $3.75 \mathrm{mg} \mathrm{As} \mathrm{L}^{-1}$ treatment. Arsenic significantly reduced tissue element content below that of the control for all elements in shoot and root tissue except for Cu. Four elements, $\mathrm{Cu}, \mathrm{Fe}, \mathrm{Mn}$ and Mo had higher element content in root than shoot tissue (Table 2).

The pattern of element accumulation in iris mirrored that of dry weight and As accumulation. For all elements

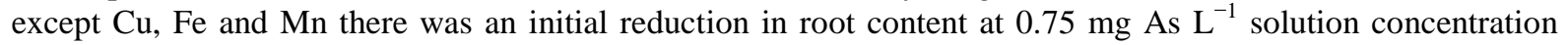
(Table 2). Iron and Mn had a similar initial reduction in root content but the differences were not significant. At higher solution $\mathrm{ACs}$ there was a $\geq$ increase in nutrient element content above that of the control. Root $\mathrm{Cu}$ content initially dropped below that in the control and remained low with increased solution As (significantly lower at $3.0 \mathrm{mg} \mathrm{As} \mathrm{L^{-1 }}$ solution only). There were no significant differences in shoot $\mathrm{Cu}$ between the control and As treatments; however, values were highest at $0.75 \mathrm{mg} \cdot \mathrm{L}^{-1}$ solution As then continuously decreased from 0.001 to $0.0004 \mathrm{mg}$ shoot $\mathrm{Cu}$ with 3.00 and $5.25 \mathrm{mg} \cdot \mathrm{L}^{-1}$ solution As, respectively. There were no significant differences found in iris shoot $\mathrm{K}, \mathrm{Mn}, \mathrm{P}$ and $\mathrm{Zn}$. Content of all shoot elements (except $\mathrm{Cu}$ ) tended to decrease at $0.75 \mathrm{mg} \cdot \mathrm{L}^{-1}$ solution As then increase at higher solution AC to $5.25 \mathrm{mg} \mathrm{As} \mathrm{L}^{-1}$.

With the exception of $\mathrm{Cu}$ there were no significant differences in marigold root element content between the control and As treatments (Table 2). For all elements, no differences in As treatments were found in marigold shoot tissue. Root $\mathrm{Cu}$ content declined by $>94 \%$ with As treatments. Although difference were not significant in shoot tissue, $\mathrm{Cu}$ declined by $>96 \%$ with As treatments. The response to As by sunflower was similar to that of marigold in that significant differences between control and As treatments were found only for root $\mathrm{Cu}$ and $\mathrm{S}$ and shoot $\mathrm{Cu}$.

No significant differences were found between control and treatments in switchgrass root tissue for all elements except K, Mo, P and Zn (Table 2). In switchgrass shoot tissue, a steady decline in element content was found with increasing solution AC. With $\mathrm{Cu}, \mathrm{K}$ and $\mathrm{P}$ the reduction at $5.25 \mathrm{mg} \cdot \mathrm{L}^{-1}$ solution As was to $<50 \%$ of that found in the zero As control.

\subsection{Translocation Percentage and Tissue Concentration}

As mentioned above an increase in solution AC led to an increase in As uptake and a decrease in total plant uptake of all elements by coreopsis (Figure 2, Table 2). Translocation from coreopsis root to shoot tissue either decreased or insignificantly decreased with increasing solution As for all elements except $\mathrm{Cu}$ and Mo (Table 3). An increase in $\mathrm{Cu}$ translocation was observed with as little as $0.75 \mathrm{mg} \cdot \mathrm{L}^{-1}$ solution As, however, with Mo the increase was insignificant. Boron, $\mathrm{Mn}$ and $\mathrm{S}$ concentration in root tissue increased and $\mathrm{Cu}$ decreased with increasing Solution As (Table 4). Generally, shoot element concentrations were not dramatically different from that found in the control. Several elements $\mathrm{Ca}, \mathrm{Mg}, \mathrm{Mn}$, Mo and S had an increase in concentration at 5.25 $\mathrm{mg} \cdot \mathrm{L}^{-1}$ solution As over that in the control. Given the large reduction in plant dry weight due to the increased As uptake, a higher tissue concentration of some elements would be expected. Chlorosis was observed on coreopsis leaves with $0.75 \mathrm{mg} \cdot \mathrm{L}^{-1}$ solution As which is consistent with the reduction in Fe concentration. Copper translocation increased as copper concentration in both root and shoot tissue decreased. Copper is a component of enzymes associated with electron transport and protection against superoxide-free radicals [32]. Arsenic toxicity has been shown to cause an increase in reactive oxygen species leading to membrane leakage [33]. In the current study shoot $\mathrm{Cu}$ was reduced by $\geq 83 \%$ and root $\mathrm{Cu}$ by $94 \%$. It is possible that reduced production of $\mathrm{Cu}$ containing enzymes used to detoxify oxygen-free radicals was a contributing factor in As toxicity at low solution As levels in coreopsis.

In tithonia, As translocation was greater at 0.75 and $2.25 \mathrm{mg} \cdot \mathrm{L}^{-1}$ solution As than with the control (Table 3). Root element concentration trended downward for all elements to the point where at $5.25 \mathrm{mg} \mathrm{As} \mathrm{L}^{-1}$ all element concentrations except $\mathrm{P}, \mathrm{S}$ and $\mathrm{Zn}$ were significantly lower than in the control (Table 3). There was an increase in shoot $\mathrm{B}, \mathrm{Ca}, \mathrm{Mg}, \mathrm{Mn}, \mathrm{P}, \mathrm{S}$ and $\mathrm{Zn}$ at $0.75 \mathrm{mg} \cdot \mathrm{L}^{-1}$ solution $\mathrm{AC}$ followed by a drop in concentration as solution As increased. Both root and shoot $\mathrm{Cu}$ were significantly reduced by $\geq 97 \%$, even at the low solution AC.

In iris there were no differences in translocation percent for any element except As and Fe (Table 3). Translocation of Fe was reduced at $3.0 \mathrm{mg} \cdot \mathrm{L}^{-1}$ As and above. There were no visible signs of chlorosis and shoot $\mathrm{Fe}$ concentrations were similar to the control at all As treatments levels (Table 4). Root tissue Ca, $\mathrm{K}$ and $\mathrm{Mg}$ concentration increased with increasing solution As; however, there were no differences in shoot concentration of these elements. Root B concentration increased at higher solution ACs whereas, shoot As did not differ from the 
Table 3. Translocation percent from root to shoot tissue for different elements in Coreopsis lanceolata, Iris savannarum, Tagetes erecta (marigold), Helianthusannuus L. (Sunflower), Panicum virgatum (Switchgrass) and Tithonia rotundiflora grown in hydroponic solution containing As concentrations from 0.0 to $5.25 \mathrm{mg} \cdot \mathrm{L}^{-1}$.

\begin{tabular}{|c|c|c|c|c|c|c|c|c|c|c|c|c|}
\hline $\begin{array}{l}\text { Solution } \\
\text { concentration } \\
\left(\mathrm{mg} \cdot \mathrm{L}^{-1}\right)\end{array}$ & As & B & $\mathrm{Ca}$ & $\mathrm{Cu}$ & $\mathrm{Fe}$ & $\mathrm{K}$ & $\mathrm{Mg}$ & Mn & Mo & $\mathrm{P}$ & $\mathrm{S}$ & $\mathrm{Zn}$ \\
\hline & \multicolumn{12}{|c|}{ Coreopsis lanceolata } \\
\hline 0.00 & $29.2 a^{\mathrm{f}}$ & 89.57 a & $85.86 a b$ & $87.60 \mathrm{~b}$ & 39.65 ns & 79.44 a & $87.28 \mathrm{~ns}$ & $87.87 \mathrm{~ns}$ & $43.42 \mathrm{~ns}$ & 70.52 a & $63.43 \mathrm{ab}$ & $70.70 \mathrm{a}$ \\
\hline 0.75 & $13.3 \mathrm{~b}$ & $82.00 \mathrm{~b}$ & $86.00 \mathrm{ab}$ & 93.32 a & $29.32 \mathrm{~ns}$ & 78.33 a & $82.07 \mathrm{~ns}$ & $85.14 \mathrm{~ns}$ & $48.88 \mathrm{~ns}$ & 68.11 a & $71.05 \mathrm{a}$ & 75.18 a \\
\hline 2.25 & $13.3 \mathrm{~b}$ & $86.69 \mathrm{ab}$ & 89.48 a & 94.68 a & $29.71 \mathrm{~ns}$ & $75.72 \mathrm{a}$ & $84.00 \mathrm{~ns}$ & $87.57 \mathrm{~ns}$ & $45.63 \mathrm{~ns}$ & $61.44 \mathrm{a}$ & $58.71 \mathrm{~b}$ & $67.06 \mathrm{a}$ \\
\hline \multirow[t]{2}{*}{5.25} & $6.8 \mathrm{~b}$ & $73.78 \mathrm{c}$ & $82.87 \mathrm{~b}$ & 96.26 a & $27.78 \mathrm{~ns}$ & $59.08 \mathrm{~b}$ & $80.75 \mathrm{~ns}$ & $88.58 \mathrm{~ns}$ & $53.58 \mathrm{~ns}$ & $50.18 \mathrm{~b}$ & $44.95 \mathrm{c}$ & $48.55 \mathrm{~b}$ \\
\hline & \multicolumn{12}{|c|}{ Iris savannarum } \\
\hline 0.00 & $40.92 \mathrm{~b}$ & $67.55 \mathrm{~ns}$ & $75.23 \mathrm{~ns}$ & $70.16 \mathrm{~ns}$ & 56.13 a & $75.67 \mathrm{~ns}$ & $72.04 \mathrm{~ns}$ & $61.22 \mathrm{~ns}$ & $60.13 \mathrm{~ns}$ & $68.56 \mathrm{~ns}$ & $69.31 \mathrm{~ns}$ & $52.67 \mathrm{~ns}$ \\
\hline 0.75 & $44.96 \mathrm{ab}$ & $70.04 \mathrm{~ns}$ & $74.28 \mathrm{~ns}$ & $68.42 \mathrm{~ns}$ & 56.94 a & $80.54 \mathrm{~ns}$ & $75.47 \mathrm{~ns}$ & $55.17 \mathrm{~ns}$ & $56.03 \mathrm{~ns}$ & $71.23 \mathrm{~ns}$ & $69.53 \mathrm{~ns}$ & $52.30 \mathrm{~ns}$ \\
\hline 2.25 & $33.74 \mathrm{~b}$ & $76.99 \mathrm{~ns}$ & $75.54 \mathrm{~ns}$ & $88.46 \mathrm{~ns}$ & $27.51 \mathrm{~b}$ & $83.33 \mathrm{~ns}$ & $73.40 \mathrm{~ns}$ & $48.27 \mathrm{~ns}$ & $76.12 \mathrm{~ns}$ & $74.48 \mathrm{~ns}$ & $73.75 \mathrm{~ns}$ & $64.78 \mathrm{~ns}$ \\
\hline \multirow[t]{2}{*}{5.25} & 69.25 a & $77.25 \mathrm{~ns}$ & $76.25 \mathrm{~ns}$ & $60.17 \mathrm{~ns}$ & $23.75 b$ & $82.61 \mathrm{~ns}$ & $75.87 \mathrm{~ns}$ & $45.24 \mathrm{~ns}$ & $67.06 \mathrm{~ns}$ & $76.82 \mathrm{~ns}$ & $74.14 \mathrm{~ns}$ & $67.39 \mathrm{~ns}$ \\
\hline & \multicolumn{12}{|c|}{ Tagetes erecta (marigold) } \\
\hline 0.00 & $17.69 \mathrm{~ns}$ & $85.37 \mathrm{ab}$ & $85.77 \mathrm{~ns}$ & $86.47 \mathrm{~ns}$ & $11.54 \mathrm{~b}$ & $91.24 \mathrm{~ns}$ & $81.61 \mathrm{~ns}$ & $48.02 \mathrm{~ns}$ & $24.20 \mathrm{~ns}$ & $94.00 \mathrm{~ns}$ & $76.10 \mathrm{~ns}$ & $71.04 \mathrm{~ns}$ \\
\hline 0.75 & $30.24 \mathrm{~ns}$ & 88.89 a & $88.10 \mathrm{~ns}$ & $87.85 \mathrm{~ns}$ & 23.77 a & $92.06 \mathrm{~ns}$ & $86.94 \mathrm{~ns}$ & $54.51 \mathrm{~ns}$ & $38.36 \mathrm{~ns}$ & $94.77 \mathrm{~ns}$ & $81.89 \mathrm{~ns}$ & $70.89 \mathrm{~ns}$ \\
\hline 2.25 & $16.64 \mathrm{~ns}$ & $87.75 \mathrm{ab}$ & $86.01 \mathrm{~ns}$ & $92.78 \mathrm{~ns}$ & $16.65 \mathrm{ab}$ & $89.80 \mathrm{~ns}$ & $83.91 \mathrm{~ns}$ & $52.34 \mathrm{~ns}$ & $26.65 \mathrm{~ns}$ & $92.79 \mathrm{~ns}$ & $79.10 \mathrm{~ns}$ & $61.46 \mathrm{~ns}$ \\
\hline \multirow[t]{2}{*}{5.25} & $38.43 \mathrm{~ns}$ & $84.47 \mathrm{~b}$ & $87.02 \mathrm{~ns}$ & $76.31 \mathrm{~ns}$ & $14.69 \mathrm{ab}$ & $89.47 \mathrm{~ns}$ & $84.22 \mathrm{~ns}$ & $57.96 \mathrm{~ns}$ & $31.37 \mathrm{~ns}$ & $93.61 \mathrm{~ns}$ & $80.10 \mathrm{~ns}$ & $68.14 \mathrm{~ns}$ \\
\hline & \multicolumn{12}{|c|}{ Helianthus annuus (sunflower) } \\
\hline 0.00 & $44.47 \mathrm{~ns}$ & $95.54 \mathrm{~ns}$ & $93.14 \mathrm{~ns}$ & $94.24 \mathrm{~ns}$ & $47.53 \mathrm{ab}$ & $90.68 \mathrm{~ns}$ & $95.33 \mathrm{~ns}$ & $62.30 \mathrm{~ns}$ & $69.04 \mathrm{~ns}$ & $92.83 \mathrm{~ns}$ & $86.34 \mathrm{~b}$ & $84.07 \mathrm{ab}$ \\
\hline 0.75 & $43.92 \mathrm{~ns}$ & $96.81 \mathrm{~ns}$ & $95.84 \mathrm{~ns}$ & $96.68 \mathrm{~ns}$ & $45.62 \mathrm{ab}$ & $93.05 \mathrm{~ns}$ & $97.06 \mathrm{~ns}$ & $71.28 \mathrm{~ns}$ & $77.03 \mathrm{~ns}$ & $92.95 \mathrm{~ns}$ & 93.88 a & 90.52 a \\
\hline 2.25 & $45.41 \mathrm{~ns}$ & $97.36 \mathrm{~ns}$ & $95.67 \mathrm{~ns}$ & $97.57 \mathrm{~ns}$ & 65.78 a & $93.09 \mathrm{~ns}$ & $97.23 \mathrm{~ns}$ & $76.15 \mathrm{~ns}$ & $74.63 \mathrm{~ns}$ & $93.35 \mathrm{~ns}$ & $91.65 \mathrm{ab}$ & $83.83 \mathrm{ab}$ \\
\hline \multirow[t]{2}{*}{5.25} & $44.88 \mathrm{~ns}$ & $95.65 \mathrm{~ns}$ & $94.45 \mathrm{~ns}$ & $93.94 \mathrm{~ns}$ & $35.98 \mathrm{~b}$ & $91.13 \mathrm{~ns}$ & $96.26 \mathrm{~ns}$ & $66.63 \mathrm{~ns}$ & $65.49 \mathrm{~ns}$ & $90.97 \mathrm{~ns}$ & 93.52 a & $78.01 \mathrm{~b}$ \\
\hline & \multicolumn{12}{|c|}{ Panicum virgatum (switchgrass) } \\
\hline 0.00 & $23.58 \mathrm{~ns}$ & 57.77 a & 33.78 a & $86.35 \mathrm{~ns}$ & $9.29 \mathrm{~ns}$ & $75.92 \mathrm{a}$ & 61.64 a & $26.70 \mathrm{~ns}$ & 43.59 a & $77.00 \mathrm{a}$ & $65.02 \mathrm{a}$ & $59.27 \mathrm{~b}$ \\
\hline 0.75 & $20.69 \mathrm{~ns}$ & 51.64 a & $31.74 \mathrm{ab}$ & $79.37 \mathrm{~ns}$ & $4.53 \mathrm{~ns}$ & 73.37 a & 59.54 a & $26.00 \mathrm{~ns}$ & 25.84 b & $70.32 \mathrm{ab}$ & 64.86 a & 70.81 a \\
\hline 2.25 & $5.00 \mathrm{~ns}$ & $49.90 \mathrm{a}$ & $29.69 \mathrm{ab}$ & $87.64 \mathrm{~ns}$ & $3.27 \mathrm{~ns}$ & $64.50 \mathrm{~b}$ & $49.85 \mathrm{ab}$ & $27.54 \mathrm{~ns}$ & 40.38 a & $65.37 \mathrm{~b}$ & 61.57 a & $56.58 \mathrm{~b}$ \\
\hline \multirow[t]{2}{*}{5.25} & $18.13 \mathrm{~ns}$ & $31.90 \mathrm{~b}$ & $17.24 \mathrm{~b}$ & $66.76 \mathrm{~ns}$ & $3.25 \mathrm{~ns}$ & $63.51 \mathrm{~b}$ & 39.96 b & $15.69 \mathrm{~ns}$ & 22.05 b & $71.04 \mathrm{ab}$ & $46.44 \mathrm{~b}$ & $35.84 \mathrm{c}$ \\
\hline & \multicolumn{12}{|c|}{ Tithonia rotundiflora } \\
\hline 0.00 & $25.93 \mathrm{~b}$ & $82.67 \mathrm{~ns}$ & $84.66 \mathrm{~ns}$ & $135.50 \mathrm{~ns}$ & $22.28 \mathrm{~ns}$ & $79.75 \mathrm{~ns}$ & $86.20 \mathrm{~ns}$ & $48.66 \mathrm{~ns}$ & $18.70 \mathrm{~ns}$ & $88.74 \mathrm{~ns}$ & $78.00 \mathrm{~ns}$ & $55.36 \mathrm{~ns}$ \\
\hline 0.75 & 45.84 a & $86.42 \mathrm{~ns}$ & $90.63 \mathrm{~ns}$ & $44.96 \mathrm{~ns}$ & $18.63 \mathrm{~ns}$ & $80.26 \mathrm{~ns}$ & $92.37 \mathrm{~ns}$ & $58.60 \mathrm{~ns}$ & $20.53 \mathrm{~ns}$ & $89.86 \mathrm{~ns}$ & $80.10 \mathrm{~ns}$ & $56.54 \mathrm{~ns}$ \\
\hline 2.25 & $49.08 \mathrm{a}$ & $88.10 \mathrm{~ns}$ & $86.51 \mathrm{~ns}$ & $52.94 \mathrm{~ns}$ & $26.60 \mathrm{~ns}$ & $86.30 \mathrm{~ns}$ & $91.52 \mathrm{~ns}$ & $46.98 \mathrm{~ns}$ & $34.38 \mathrm{~ns}$ & $85.28 \mathrm{~ns}$ & $82.66 \mathrm{~ns}$ & $57.19 \mathrm{~ns}$ \\
\hline 5.25 & $31.80 \mathrm{ab}$ & $82.54 \mathrm{~ns}$ & $85.96 \mathrm{~ns}$ & $49.39 \mathrm{~ns}$ & $11.12 \mathrm{~ns}$ & $77.90 \mathrm{~ns}$ & 89.52 ns & $47.26 \mathrm{~ns}$ & $31.40 \mathrm{~ns}$ & $83.62 \mathrm{~ns}$ & $76.29 \mathrm{~ns}$ & $40.82 \mathrm{~ns}$ \\
\hline
\end{tabular}

${ }^{\mathrm{I}}$ Numbers in any individual column followed by the same letter are not significantly different at $P=0.05$; ns, no significant difference. 
Table 4. The effect of solution As concentration on element concentration $\left(\mathrm{mg} \cdot \mathrm{kg}^{-1}\right)$ in shoot and root tissue.

\begin{tabular}{|c|c|c|c|c|c|c|c|c|c|c|c|}
\hline $\begin{array}{l}\text { Solution As } \\
\text { concentration } \\
\left(\mathrm{mg} \cdot \mathrm{L}^{-1}\right)\end{array}$ & B & $\mathrm{Ca}$ & $\mathrm{Cu}$ & $\mathrm{Fe}$ & K & $\mathrm{Mg}$ & $\mathrm{Mn}$ & Mo & $\mathrm{P}$ & S & $\mathrm{Zn}$ \\
\hline & \multicolumn{11}{|c|}{ Coreopsis lanceolata } \\
\hline & \multicolumn{11}{|c|}{ Shoot } \\
\hline 0.00 & $42.0 \mathrm{~ns}^{\mathrm{T}}$ & $16291 \mathrm{~b}$ & 0.623 a & 65.42 a & $66063 \mathrm{~b}$ & $6536 \mathrm{~b}$ & $46.09 \mathrm{c}$ & $0.5 \mathrm{~b}$ & 5561 a & $2744 \mathrm{~d}$ & $26.80 \mathrm{~b}$ \\
\hline 0.75 & $39.4 \mathrm{~ns}$ & $16922 \mathrm{~b}$ & $0.108 \mathrm{~b}$ & $51.27 \mathrm{~b}$ & $72127 \mathrm{a}$ & 5498 c & $71.43 \mathrm{~b}$ & $0.8 \mathrm{~b}$ & 5356 a & 6145 a & $47.65 \mathrm{a}$ \\
\hline 2.25 & $43.7 \mathrm{~ns}$ & $17289 \mathrm{~b}$ & 0.040 c & $45.26 \mathrm{~b}$ & $63168 \mathrm{~b}$ & $6537 \mathrm{~b}$ & $60.87 \mathrm{~b}$ & $0.9 \mathrm{~b}$ & $4380 \mathrm{~b}$ & 3380 c & $24.47 \mathrm{~b}$ \\
\hline \multirow[t]{2}{*}{5.25} & $37.8 \mathrm{~ns}$ & 20470 a & 0.023 c & $49.43 \mathrm{~b}$ & 53095 c & 7779 a & 110.97 a & $1.7 \mathrm{a}$ & $3765 b$ & $3536 \mathrm{~b}$ & $25.49 \mathrm{~b}$ \\
\hline & \multicolumn{11}{|c|}{ Root } \\
\hline 0.00 & $12.6 \mathrm{~b}$ & $6992 \mathrm{~ns}$ & 0.305 a & $269.80 \mathrm{~ns}$ & $44722 \mathrm{~ns}$ & $2470 \mathrm{~ns}$ & $16.83 \mathrm{~b}$ & $2.0 \mathrm{~ns}$ & $6018 \mathrm{~ns}$ & $4114 \mathrm{~b}$ & $29.00 \mathrm{~ns}$ \\
\hline 0.75 & $18.8 \mathrm{a}$ & 5393 ns & $0.016 \mathrm{~b}$ & $299.30 \mathrm{~ns}$ & $44446 \mathrm{~ns}$ & $2619 \mathrm{~ns}$ & 26.42 a & $2.0 \mathrm{~ns}$ & $5800 \mathrm{~ns}$ & $5590 \mathrm{ab}$ & $35.18 \mathrm{~ns}$ \\
\hline 2.25 & $16.8 \mathrm{a}$ & 5243 ns & $0.007 \mathrm{~b}$ & $439.70 \mathrm{~ns}$ & 51346 ns & 3109 ns & $23.72 \mathrm{a}$ & $3.3 \mathrm{~ns}$ & $6981 \mathrm{~ns}$ & $5998 \mathrm{ab}$ & 30.03 ns \\
\hline \multirow[t]{3}{*}{5.25} & $19.7 \mathrm{a}$ & $6241 \mathrm{~ns}$ & $0.002 \mathrm{~b}$ & $251.40 \mathrm{~ns}$ & $54962 \mathrm{~ns}$ & $2726 \mathrm{~ns}$ & $17.87 \mathrm{~b}$ & $2.1 \mathrm{~ns}$ & $5608 \mathrm{~ns}$ & 6568 a & $40.15 \mathrm{~ns}$ \\
\hline & \multicolumn{11}{|c|}{ Iris (Iris savannarum) } \\
\hline & \multicolumn{11}{|c|}{ Shoot } \\
\hline 0.00 & $46.3 \mathrm{~ns}$ & 10143 ns & 6.758 a & $94.03 \mathrm{~ns}$ & $65272 \mathrm{~ns}$ & $4189 \mathrm{~ns}$ & $12.59 \mathrm{~ns}$ & $0.9 \mathrm{ab}$ & $7355 \mathrm{~ns}$ & $3384 \mathrm{~b}$ & $26.02 \mathrm{~ns}$ \\
\hline 0.75 & $44.0 \mathrm{~ns}$ & $9336 \mathrm{~ns}$ & $1.157 \mathrm{~b}$ & $71.67 \mathrm{~ns}$ & $64668 \mathrm{~ns}$ & 3978 ns & $7.39 \mathrm{~ns}$ & $0.9 \mathrm{ab}$ & $6745 \mathrm{~ns}$ & 4634 a & $22.35 \mathrm{~ns}$ \\
\hline 3.00 & $43.6 \mathrm{~ns}$ & $8478 \mathrm{~ns}$ & $0.218 \mathrm{~b}$ & $80.67 \mathrm{~ns}$ & $65369 \mathrm{~ns}$ & $3608 \mathrm{~ns}$ & $8.98 \mathrm{~ns}$ & $1.3 \mathrm{a}$ & 6459 ns & $4364 \mathrm{ab}$ & $22.34 \mathrm{~ns}$ \\
\hline \multirow[t]{2}{*}{5.25} & $46.5 \mathrm{~ns}$ & 8655 ns & $0.138 \mathrm{~b}$ & $69.67 \mathrm{~ns}$ & $61873 \mathrm{~ns}$ & $3758 \mathrm{~ns}$ & $8.71 \mathrm{~ns}$ & $0.7 \mathrm{~b}$ & $6596 \mathrm{~ns}$ & $4306 \mathrm{ab}$ & $20.27 \mathrm{~ns}$ \\
\hline & \multicolumn{11}{|c|}{ Root } \\
\hline 0.00 & $26.8 \mathrm{~b}$ & $3895 \mathrm{~b}$ & $1.682 \mathrm{a}$ & $103.90 \mathrm{~d}$ & $21294 \mathrm{~d}$ & $1844 \mathrm{~d}$ & $9.72 \mathrm{~b}$ & $0.9 \mathrm{~b}$ & $4168 \mathrm{~ns}$ & $1856 \mathrm{~b}$ & 39.55 a \\
\hline 0.75 & $34.0 \mathrm{a}$ & $4698 \mathrm{~b}$ & $0.368 \mathrm{~b}$ & $116.80 \mathrm{c}$ & 23012 c & 2195 c & $9.06 \mathrm{~b}$ & $1.4 \mathrm{a}$ & $4863 \mathrm{~ns}$ & 3717 a & 43.27 a \\
\hline 3.00 & $29.1 \mathrm{ab}$ & 6033 a & $0.054 \mathrm{~d}$ & 817.00 a & 28177 b & $2819 b$ & 27.49 a & $0.9 \mathrm{~b}$ & $4978 \mathrm{~ns}$ & 3573 a & $28.00 \mathrm{~b}$ \\
\hline \multirow[t]{3}{*}{5.25} & 33.9 a & 6703 a & 0.065 c & $680.50 \mathrm{~b}$ & 33103 a & 2989 a & 24.29 a & $0.8 \mathrm{~b}$ & $4865 \mathrm{~ns}$ & 3936 a & $27.26 \mathrm{~b}$ \\
\hline & \multicolumn{11}{|c|}{ Marigold (Tagetes erecta) } \\
\hline & \multicolumn{11}{|c|}{ Shoot } \\
\hline 0.00 & $32.5 \mathrm{~ns}$ & $14868 \mathrm{~b}$ & 5.460 a & $62.31 \mathrm{~ns}$ & $39006 \mathrm{~ns}$ & $2479 a b$ & $57.15 \mathrm{~ns}$ & $0.4 \mathrm{~ns}$ & $6132 a b$ & 2814 ns & $135.88 \mathrm{~ns}$ \\
\hline 0.75 & $36.7 \mathrm{~ns}$ & $12879 \mathrm{~b}$ & $0.602 \mathrm{~b}$ & $95.39 \mathrm{~ns}$ & 32743 ns & $2232 \mathrm{~b}$ & $54.11 \mathrm{~ns}$ & $0.5 \mathrm{~ns}$ & $5761 \mathrm{~b}$ & $3157 \mathrm{~ns}$ & $113.72 \mathrm{~ns}$ \\
\hline 3.75 & $35.3 \mathrm{~ns}$ & $14332 \mathrm{~b}$ & $0.512 \mathrm{~b}$ & $71.49 \mathrm{~ns}$ & 35601 ns & $2531 \mathrm{ab}$ & $65.33 \mathrm{~ns}$ & $0.4 \mathrm{~ns}$ & $5666 \mathrm{~b}$ & $3401 \mathrm{~ns}$ & $93.09 \mathrm{~ns}$ \\
\hline \multirow[t]{2}{*}{5.25} & $30.6 \mathrm{~ns}$ & 18767 a & $0.353 \mathrm{~b}$ & $63.81 \mathrm{~ns}$ & 38559 ns & 2709 a & $70.92 \mathrm{~ns}$ & $0.5 \mathrm{~ns}$ & 7228 a & 3872 ns & $84.19 \mathrm{~ns}$ \\
\hline & \multicolumn{11}{|c|}{ Root } \\
\hline 0.00 & $18.7 \mathrm{~ns}$ & 8794 ns & $5.455 \mathrm{a}$ & $1592.70 \mathrm{~ns}$ & 12289 ns & $1864 \mathrm{ab}$ & $222.23 \mathrm{~ns}$ & $4.0 \mathrm{~ns}$ & $1297 \mathrm{~ns}$ & $3140 \mathrm{~ns}$ & $161.46 \mathrm{~ns}$ \\
\hline 0.75 & $21.3 \mathrm{~ns}$ & $8171 \mathrm{~ns}$ & $0.393 \mathrm{~b}$ & $1472.40 \mathrm{~ns}$ & 14749 ns & $1583 \mathrm{~b}$ & $213.93 \mathrm{~ns}$ & $3.8 \mathrm{~ns}$ & $1600 \mathrm{~ns}$ & $3401 \mathrm{~ns}$ & $235.36 \mathrm{~ns}$ \\
\hline 3.75 & $18.9 \mathrm{~ns}$ & 9211 ns & $0.167 \mathrm{~b}$ & $1488.90 \mathrm{~ns}$ & 15482 ns & 1885 a & $231.41 \mathrm{~ns}$ & $3.9 \mathrm{~ns}$ & 1754 ns & $4749 \mathrm{~ns}$ & $240.64 \mathrm{~ns}$ \\
\hline 5.25 & $21.4 \mathrm{~ns}$ & 10172 ns & $0.427 \mathrm{~b}$ & $1881.70 \mathrm{~ns}$ & 17427 ns & 1904 a & $184.32 \mathrm{~ns}$ & $4.6 \mathrm{~ns}$ & 1853 ns & $3705 \mathrm{~ns}$ & $153.74 \mathrm{~ns}$ \\
\hline
\end{tabular}




\section{Continued}

Sunflower (Helianthus annuus L.)

\begin{tabular}{|c|c|c|c|c|c|c|c|c|c|c|c|}
\hline \multirow[b]{2}{*}{0.00} & \multicolumn{11}{|c|}{ Shoot } \\
\hline & $66.9 \mathrm{~b}$ & 14722 c & 6.687 a & 70.33 a & 41071 c & $4183 \mathrm{~b}$ & $30.70 \mathrm{~ns}$ & $0.8 \mathrm{ab}$ & $6613 \mathrm{~b}$ & $3647 \mathrm{~b}$ & $75.62 \mathrm{~b}$ \\
\hline 0.75 & $88.0 \mathrm{a}$ & 19063 a & $0.618 \mathrm{~b}$ & $60.61 \mathrm{ab}$ & 49657 a & 5208 a & $42.57 \mathrm{~ns}$ & $1.0 \mathrm{a}$ & 8329 a & 6282 a & $131.08 \mathrm{a}$ \\
\hline 3.75 & $78.4 \mathrm{ab}$ & 15714 bc & $0.150 \mathrm{~b}$ & $60.39 \mathrm{ab}$ & $45550 \mathrm{~b}$ & 5174 a & $32.06 \mathrm{~ns}$ & $0.7 \mathrm{~b}$ & 8439 a & $4172 \mathrm{~b}$ & $100.14 \mathrm{~b}$ \\
\hline 5.25 & $69.5 \mathrm{ab}$ & $17991 \mathrm{ab}$ & $0.128 \mathrm{~b}$ & $54.40 \mathrm{~b}$ & 42736 bc & 4973 a & $41.79 \mathrm{~ns}$ & $0.8 \mathrm{ab}$ & $7206 \mathrm{ab}$ & $4675 \mathrm{~b}$ & 88.72 b \\
\hline \multicolumn{12}{|c|}{ Root } \\
\hline 0.00 & $18.8 \mathrm{ab}$ & $6728 \mathrm{~ns}$ & $1.707 \mathrm{a}$ & $524.50 \mathrm{~ns}$ & $27056 \mathrm{~ns}$ & 1282 ns & 115.66 ns & $2.3 \mathrm{~ns}$ & $3357 \mathrm{~b}$ & $3761 \mathrm{~ns}$ & $87.56 \mathrm{~b}$ \\
\hline 0.75 & $22.1 \mathrm{a}$ & $6130 \mathrm{~ns}$ & $0.133 \mathrm{~b}$ & $694.30 \mathrm{~ns}$ & 32707 ns & $1191 \mathrm{~ns}$ & 133.56 ns & $2.4 \mathrm{~ns}$ & 5394 a & $2787 \mathrm{~ns}$ & $96.64 \mathrm{~b}$ \\
\hline 3.75 & $18.1 \mathrm{~b}$ & $6172 \mathrm{~ns}$ & $0.033 \mathrm{~b}$ & $464.50 \mathrm{~ns}$ & 30318 ns & $1282 \mathrm{~ns}$ & 89.85 ns & $2.2 \mathrm{~ns}$ & 5347 a & $3468 \mathrm{~ns}$ & $168.36 \mathrm{a}$ \\
\hline 5.25 & $18.8 \mathrm{ab}$ & $6439 \mathrm{~ns}$ & $0.042 \mathrm{~b}$ & $700.80 \mathrm{~ns}$ & 27887 ns & 1193 ns & 120.79 ns & $3.1 \mathrm{~ns}$ & $4655 \mathrm{ab}$ & $2106 \mathrm{~ns}$ & $153.49 \mathrm{a}$ \\
\hline
\end{tabular}
Switchgrass (Panicum virgatum)

Shoot

\begin{tabular}{|c|c|c|c|c|c|c|c|c|c|c|c|}
\hline 0.00 & $14.1 \mathrm{~ns}$ & $4564 \mathrm{~ns}$ & $2.670 \mathrm{a}$ & 81.79 ns & 33942 b & 5238 c & $13.30 \mathrm{~b}$ & $0.5 \mathrm{~ns}$ & $5493 \mathrm{~ns}$ & $1968 \mathrm{~d}$ & $20.93 \mathrm{~b}$ \\
\hline 0.75 & $14.3 \mathrm{~ns}$ & $5039 \mathrm{~ns}$ & $0.447 \mathrm{~b}$ & $75.42 \mathrm{~ns}$ & $34860 \mathrm{a}$ & 5561 a & $17.51 \mathrm{~b}$ & $0.4 \mathrm{~ns}$ & $5771 \mathrm{~ns}$ & 3553 b & 20.74 c \\
\hline 3.00 & $13.2 \mathrm{~ns}$ & 5337 ns & $0.165 \mathrm{~b}$ & $77.15 \mathrm{~ns}$ & 33184 c & $5534 \mathrm{~b}$ & 26.75 a & $0.5 \mathrm{~ns}$ & $5899 \mathrm{~ns}$ & 4581 a & 21.52 a \\
\hline 5.25 & $13.3 \mathrm{~ns}$ & 4403 ns & $0.162 \mathrm{~b}$ & 73.15 ns & $25552 \mathrm{~d}$ & $3714 \mathrm{~d}$ & $17.92 \mathrm{~b}$ & $0.5 \mathrm{~ns}$ & 4904 ns & 2999 c & $13.55 \mathrm{~d}$ \\
\hline \multicolumn{12}{|c|}{ Root } \\
\hline 0.00 & $16.1 \mathrm{~b}$ & $14095 \mathrm{ab}$ & 0.660 a & $2216.60 \mathrm{~ns}$ & 19557 a & $4790 \mathrm{ab}$ & $67.52 \mathrm{~ns}$ & $1.0 \mathrm{ab}$ & 2910 c & $1845 \mathrm{~b}$ & 26.94 a \\
\hline 0.75 & $14.4 \mathrm{~b}$ & $11786 \mathrm{~b}$ & $0.055 \mathrm{~b}$ & $2018.40 \mathrm{~ns}$ & 17152 c & 3925 b & $55.18 \mathrm{~ns}$ & $1.4 \mathrm{a}$ & 3576 a & $2382 \mathrm{ab}$ & $10.59 \mathrm{~b}$ \\
\hline 3.00 & $14.0 \mathrm{~b}$ & $14426 \mathrm{ab}$ & $0.025 \mathrm{~b}$ & $2699.10 \mathrm{~ns}$ & $19271 \mathrm{~b}$ & 6021 a & 83.65 ns & $0.8 \mathrm{~b}$ & 3313 b & 2948 a & $17.87 \mathrm{ab}$ \\
\hline 5.25 & $21.9 \mathrm{a}$ & 15755 a & $0.022 \mathrm{~b}$ & $2364.30 \mathrm{~ns}$ & $11254 \mathrm{~d}$ & 3874 b & $71.79 \mathrm{~ns}$ & $1.4 \mathrm{a}$ & $1603 \mathrm{~d}$ & 2677 a & $16.76 \mathrm{ab}$ \\
\hline
\end{tabular}

Tithonia rotundiflora

Shoot

\begin{tabular}{llllllllllll}
0.00 & $52.6 \mathrm{a}$ & $23271 \mathrm{a}$ & $1.817 \mathrm{a}$ & $147.88 \mathrm{~ns}$ & $56961 \mathrm{a}$ & $7733 \mathrm{ab}$ & $22.15 \mathrm{~b}$ & $0.9 \mathrm{~ns}$ & $11580 \mathrm{a}$ & $3309 \mathrm{~b}$ & $23.90 \mathrm{~b}$ \\
0.75 & $60.0 \mathrm{a}$ & $25929 \mathrm{a}$ & $0.030 \mathrm{~b}$ & $107.34 \mathrm{~ns}$ & $40956 \mathrm{~b}$ & $9130 \mathrm{a}$ & $33.22 \mathrm{a}$ & $0.7 \mathrm{~ns}$ & $14762 \mathrm{a}$ & $6047 \mathrm{a}$ & $25.62 \mathrm{a}$ \\
2.25 & $37.3 \mathrm{~b}$ & $12593 \mathrm{~b}$ & $0.018 \mathrm{c}$ & $84.03 \mathrm{~ns}$ & $26679 \mathrm{c}$ & $5926 \mathrm{bc}$ & $18.28 \mathrm{~b}$ & $0.8 \mathrm{~ns}$ & $5755 \mathrm{~b}$ & $3157 \mathrm{~b}$ & $10.08 \mathrm{c}$ \\
3.75 & $28.6 \mathrm{~b}$ & $10964 \mathrm{~b}$ & $0.018 \mathrm{c}$ & $120.91 \mathrm{~ns}$ & $24460 \mathrm{~d}$ & $5148 \mathrm{c}$ & $18.00 \mathrm{~b}$ & $0.8 \mathrm{~ns}$ & $5404 \mathrm{~b}$ & $3640 \mathrm{~b}$ & $7.35 \mathrm{~d}$ \\
& & & & & & & & & & & \\
0.00 & $12.0 \mathrm{a}$ & $4693 \mathrm{a}$ & $1.725 \mathrm{a}$ & $1871.00 \mathrm{a}$ & $21414 \mathrm{a}$ & $1465 \mathrm{a}$ & $29.28 \mathrm{a}$ & $14.4 \mathrm{a}$ & $1955 \mathrm{~ns}$ & $1632 \mathrm{~ns}$ & $22.81 \mathrm{~ns}$ \\
0.75 & $10.8 \mathrm{a}$ & $2909 \mathrm{ab}$ & $0.045 \mathrm{~b}$ & $430.30 \mathrm{~b}$ & $10983 \mathrm{ab}$ & $814 \mathrm{ab}$ & $26.09 \mathrm{ab}$ & $2.9 \mathrm{~b}$ & $1767 \mathrm{~ns}$ & $1488 \mathrm{~ns}$ & $22.09 \mathrm{~ns}$ \\
2.25 & $5.5 \mathrm{~b}$ & $2242 \mathrm{~b}$ & $0.015 \mathrm{~b}$ & $346.50 \mathrm{~b}$ & $5174 \mathrm{~b}$ & $649 \mathrm{~b}$ & $24.16 \mathrm{ab}$ & $1.8 \mathrm{~b}$ & $1162 \mathrm{~ns}$ & $772 \mathrm{~ns}$ & $11.24 \mathrm{~ns}$ \\
3.75 & $4.7 \mathrm{~b}$ & $1399 \mathrm{~b}$ & $0.013 \mathrm{~b}$ & $861.50 \mathrm{~b}$ & $5054 \mathrm{~b}$ & $476 \mathrm{~b}$ & $15.21 \mathrm{~b}$ & $1.5 \mathrm{~b}$ & $867 \mathrm{~ns}$ & $782 \mathrm{~ns}$ & $6.99 \mathrm{~ns}$ \\
\hline
\end{tabular}

${ }^{\mathrm{I}}$ Numbers in an individual column followed by the same letter are not significantly different at $\mathrm{P}=0.05$; ns $=$ no significant difference. 
control. Both root and shoot concentrations of S increased with an increase in solution As. Tissue Cu concentration was significantly lower than that in the control for all solution As levels. Considering the non-significant drop in total iris shoot $\mathrm{Cu}$ content (Table 2), Cu deficiency if present, may have been slight. Copper's biochemical function in plants is mainly as an enzyme activator [32] in oxidation/reduction reactions. Given that there was an increase in root Fe and Mn concentration and no differences in shoot Fe, Mn and Zn tissue concentrations (Table 3), there were likely adequate levels of these nutrients in the plant.

In marigold, a difference in translocation percent from that in the control was found only in the 0.75 solution As treatment for Fe (Table 3). Root and shoot $\mathrm{Cu}$ concentration decreased below the control level with addition of As (Table 4). For the remaining elements, there were no significant differences in tissue concentration between the controls and As treatments for all except shoot Ca in the 5.25 solution As treatment. Non-significant but higher root and shoot $\mathrm{S}$ concentrations were found in As treatments than in the control.

Sunflower translocation percent in the control was similar to treatments for all elements except S (Table 3). At 0.75 and $5.25 \mathrm{mg} \cdot \mathrm{L}^{-1}$ As, higher $\mathrm{S}$ translocation was found between root to shoot tissue. There was no difference in root concentration of $\mathrm{Ca}, \mathrm{K}$ and $\mathrm{Mg}$ (Table 4); these elements had higher shoot tissue concentrations in As treated than in control plants. Phosphorus and Zn root tissue concentrations in As treatments were $\geq$ that found in the control. Tissue Cu concentration decreased significantly below that found in the control in all root and shoot As treatments. Shoot element concentrations in As treatments were $\geq$ that found in the control for all elements except $\mathrm{Cu}$ and $\mathrm{Fe}$. Most shoot tissue element concentrations were highest at a solution AC of 0.75 $\mathrm{mg} \cdot \mathrm{L}^{-1}$. At higher solution, As levels remained $\geq$ that found in the control. Shoot Fe levels gradually decreased at higher As levels until at $5.25 \mathrm{mg} \cdot \mathrm{L}^{-1}$ As the Fe concentration became significantly lower than that in the control.

There were few differences in switchgrass translocation percent; the general trend was lower translocation in the high As treatment. Root concentrations of $\mathrm{Ca}, \mathrm{Fe}, \mathrm{Mg}, \mathrm{Mn}$ and Mo in the control were similar to that found in As treatments (Table 4). Phosphorus concentration initially increased with As additions up to $5.25 \mathrm{mg} \mathrm{As} \mathrm{L}^{-1}$, at which point root tissue P levels dropped below that of the control. Most shoot element concentrations in As treated plants were similar to concentrations found in the control. Potassium and $\mathrm{Mg}$ had an initial increase in shoot concentration followed by a decline in concentration from that point with increasing solution As. Both root and shoot $\mathrm{S}$ concentrations were higher in As treated plants than in the control. Tissue $\mathrm{S}$ increased with exposure up to $5.25 \mathrm{mg} \cdot \mathrm{L}^{-1}$ then it began to decline. Copper concentration was significantly below that of the control at all levels of As exposure.

\section{Discussion}

\subsection{Ca, $\mathrm{K}$ and $\mathrm{Mg}$}

Calcium uptake is dependent on young root tips and is transported to the shoot by the transpiration stream [32]. Arsenic toxicity had a varying effect on $\mathrm{Ca}, \mathrm{K}$ and $\mathrm{Mg}$ concentration. Root Ca concentration increased with exposure to As in cordgrass (Spartina densiflora), winter wheat (Triticum aestivum) and castor bean (Ricinus communis) but there was a decrease in tissue Ca with As exposure in Barley (Hordeum vulgare) and Pterisvittata [34]-[38]. Liu et al. [35] and Melo et al. [36], discovered an increase in shoot Ca in wheat and castor bean. The effect of As toxicity on plant Ca levels is generally thought to result from reduced transpiration affecting transport of Ca up through the plant [32]. A high amount of $\mathrm{K}$ and $\mathrm{Mg}$ in the growth medium can compete with Ca for plant uptake. However, in this study the Ca/Mg ratio in plant tissue did not vary much in any of the species. Potassium and Mg tissue concentrations generally followed that of $\mathrm{Ca}$; an increase or decrease in concentration compared to the control was similar or not significantly different for all species and tissue type except for coreopsis shoot $\mathrm{K}$ and switchgrass root $\mathrm{Ca}$. Uptake of $\mathrm{Ca}, \mathrm{K}$ and $\mathrm{Mg}$ was likely influenced by the toxic effect of As on root functions. In addition, reduced growth limited the demand for $\mathrm{Ca}, \mathrm{K}$ and $\mathrm{Mg}$ and contributed to low uptake [22]. As had little effect on $\mathrm{Ca}, \mathrm{K}$ and $\mathrm{Mg}$ transportation to the shoot at any but the highest As exposure rate.

With the exception of tithonia, $\mathrm{Ca}, \mathrm{K}$ and $\mathrm{Mg}$ tissue concentrations differed little with changes in tissue AC from that found in controls. In the As sensitive plant tithonia a reduction in $\mathrm{Ca}, \mathrm{K}$ and $\mathrm{Mg}$ reflects a general disruption of metabolic functions. Singh et al. [39], reported a reduction in membrane stability with increased exposure to As. Reduced tissue Ca levels found may be related to As induced membrane stability; leaky membranes may be related to the low accumulation of $\mathrm{K}$ and $\mathrm{Mg}$ found in tithonia. 


\subsection{Phosphorus}

Phosphate and arsenate are taken by a common carrier [40]. Phosphorous uptake concentrations are controlled by a high affinity carrier at low solution $\mathrm{P}$ and a low affinity carrier at high solution $\mathrm{P}$. These carriers have a higher affinity for $\mathrm{P}$ than As, thus more $\mathrm{P}$ than As should enter the cell. Since As is similar to $\mathrm{P}$ it should be able to replace it in many cellular functions [37]. Arsenic however cannot replace the role of $\mathrm{P}$ in energy transfer [25] [41]. As As continues to replace $P$ a plant may respond as if a P deficiency exists and increase uptake. In contrast, a defensive response to increasing As, is to suppress the P/As high affinity carrier when tissue $\mathrm{P}$ level are sufficient [42]. Based on this, the effect of As on P status may depend on plant species and the amount of As and $\mathrm{P}$ available for uptake. In this study tissue $\mathrm{P}$ concentration generally was similar to or higher than that found in

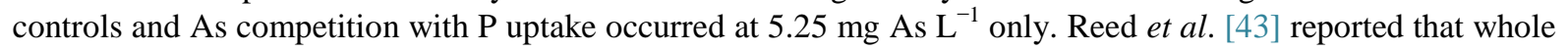
plant $\mathrm{P}$ accumulation tended to increase in iris and marigold with increasing tissue As. In these plants there appears to be no suppression of P/As uptake and P uptake is consistent with the scenario proposed by Cox [41].

\subsection{Sulfur}

Sulfur is an essential constituent in glutathione and phytochelatins [32]. These S containing compounds are capable of reducing As and chelating it for compartmentalization in a vacuole [32] [44] [45]. An increase in S or S containing compounds with an increase in As was reported for castor bean [36], Chilopsis linearis [46] and Ceratophyllumdemersum [45]. In this study S concentration increased with higher tissue As. Sulfur uptake tended to spike with exposure to low levels of As, and tissue $S$ concentration was higher than, or in the case of sunflower roots, equal to that found in controls. This is consistent with the role of $\mathrm{S}$ in detoxification through reduction and chelation of As. However, S concentration tended to peak then decline at the highest solution AC. Rausch and Wachter [47] felt than increased glutathione and phytochelatin production used in As detoxification would limit $\mathrm{S}$ needed for normal metabolic functions. This could explain the initial increase followed by a subsequent reduction in tissue $\mathrm{S}$ when uptake could not supply enough $\mathrm{S}$ for both detoxification and normal metabolic needs.

\subsection{Micronutrients}

Boron is taken up by plants with the flow of water through the roots and is relatively immobile in plants [32]. Plant species in our study, where dry weight decreased with increasing exposure to As, B uptake and translocation percentage also were reduced. Older leaves on these plants tended to show signs of wilting (curled leaves and loss of turgor). Plant species that were not as sensitive to As had dry weights, uptake and tissue concentration levels similar to the controls. These plants showed no visual signs of water stress. Singh et al. [39] reported membrane stability decreased with increasing exposure to As. The effect of As on plant B status is likely a result of membrane leakage and overall tissue damage leading to a reduction in transpiration.

Molybdenum uptake is reduced by competition with sulfate ions and enhanced by the presence of phosphate ions [32]. In this study, Mo and S uptake move in unison; an increase or decrease in S uptake was mirrored by a similar change in Mo uptake. Plant species which maintained dry weights as the AC increased also maintained Mo status similar to that found in control treatments. Sensitive species had a reduction in uptake, but only with tithonia was tissue concentration lower than in the control. The effect of As on Mo uptake is attributed to As damage to roots that was observed at harvest.

Iron and Mn are constituents in a variety of enzymes [32]. The effect of As on dry weight likely limited demand for Fe and Mn in sensitive species. Leaf chlorosis was observed in coreopsis, tithonia and switchgrass. Chlorosis is a symptom for $\mathrm{Mg}, \mathrm{Mn}$ and Fe deficiencies. Shoot Mg and Mn concentrations tended to increase with increasing As exposure, whereas Fe tended to decrease. Arsenic induced Fe deficiency was likely the primary cause of chlorosis. However, As toxicity causes a breakdown in membrane stability [39] and a general decline in mineral uptake; As induced reductions in $\mathrm{Zn}$, Mn or Mg would contribute to chlorosis. Changes in root Fe concentration were not matched in shoot Fe concentration and As seemed to affect transport of Fe from root to shoot. This is in agreement with Carbonell-Barrachina et al. [22] and Shaibur et al. [37], who reported similar As effects on the translocation of Fe.

Zinc is used in a number of enzymes and functions similarly to Mn and Mg as an enzyme activator [32]. Arsenic induced dry weight reductions also reduced Zn uptake. Increased As exposure decreased Zn translocation 
percent as well. Zinc is required for tryptophan synthesis as a precursor to the growth hormone auxin. Rosetting, a common Zn deficiency symptom, was observed in several species.

Copper is used as a constituent in electron transport proteins and oxidation/reduction reactions [32]. Most notably, $\mathrm{Cu}$ is used to neutralize reactive oxygen species through $\mathrm{Cu} / \mathrm{Zn}$ superoxide dismutase (Cu/ZnSOD) [48]. This enzyme protects the cell membrane from attack by superoxide radicals. In this study, tissue Cu concentration declined greatly ( $\leq 20 \%$ of control) upon exposure to As at the lowest level. Graham et al. [49] reported that under $\mathrm{Cu}$ deficiency, efficient cultivars can produce normal yield at or near the critical concentration of $\mathrm{Cu}$ for growth. Iris, marigold and sunflower experienced normal growth despite a large reduction in tissue Cu concentration. $\mathrm{Cu}$ usage in cellular functions in these species may be very efficient. Low $\mathrm{Cu}$ status with low exposure to As implies that $\mathrm{Cu}$ deficiency is one of the initial effects of As toxicity. Photosynthesis, respiration, lignification, and superoxide radical neutralization can all be compromised due to this interaction. Copper is a strong competitor with other metals for protein binding sites, however, very little free $\mathrm{Cu}$ is found in the cytoplasm [50]-[52]. In yeast (Saccharomyces cerevisiae), a Cu chaperone is required for transport within the cell and formation of $\mathrm{Cu} / \mathrm{ZnSOD}$ [53]. The $\mathrm{Cu}$ chaperone requires S rich proteins to function. Arsenic detoxification requires binding As to S-rich glutathione and phytochelatins [32] [44] [45]. High S use for As detoxification may be a factor limiting tissue $\mathrm{Cu}$ by suppressing production of the $\mathrm{Cu}$ chaperone.

\subsection{Iris}

The response of iris to As toxicicty was unique among the ornamentals studied. There was an initial drop in growth at low As exposure but enhanced growth at higher non-lethal exposure levels.

Arsenic is known to act as an analog to P in high-affinity uptake sites and substitute for P in certain metabolic processes [40]. Iris initial low growth with low As exposure maybe due to competition with $\mathrm{P}$ for high-affinity sites; in the process of acquiring P, As was also taken up. If As substituted for P in cellular functions, a P limitation would lead to a growth inhibition. At higher ACs a suppression of high-affinity P uptake may reduce As uptake. Meharg and Mcnair [42] reported As competition with P and a suppression of the high-affinity P uptake system as a mechanism of As tolerance in Holcus lanatus. Arsenic does not compete as effectively with $\mathrm{P}$ for low-affinity uptake sites allowing for P metabolism to occur with less interference from As. This may have led to increased growth over the control.

At low ACs $\mathrm{Cu}$ uptake is disrupted more than other elements. Translocation percent is similar to control and dry weight, after an initial decline, increased to levels higher than that of the control. This implies tissue $\mathrm{Cu}$ is used efficiently. One function of $\mathrm{Cu}$ is activating $\mathrm{Cu} / \mathrm{Zn}$ superoxide dismutase (SOD) for removal of reactive oxygen species; however, Fe and MnSOD enzymes can perform the same function. At $0.75 \mathrm{mg} \cdot \mathrm{L}^{-1}$ solution As, the need for Fe and MnSOD to take over a part of the function of $\mathrm{Cu} / \mathrm{ZnSOD}$ may contribute to reduced growth. Above $3.0 \mathrm{mg} \cdot \mathrm{L}^{-1}$ solution As, Fe and $\mathrm{Mn}$ accumulation increases and root concentrations increase dramatically; shoot concentrations are no different than that found in the control. If $\mathrm{Cu}$ uptake is indeed limiting growth at $0.75 \mathrm{mg} \cdot \mathrm{L}^{-1}$ solution As, at higher As levels higher $\mathrm{Fe}$ and $\mathrm{Mn}$ uptake could result in adequate SOD activity. Perhaps some substitution of $\mathrm{Fe}$ for $\mathrm{Cu}$ in other enzymes occurs.

Increases in iris total plant $\mathrm{S}$ with increasing exposure to As implies $\mathrm{S}$ is available for phytochelatin production leading to As detoxification. Increases in root Ca with increasing exposure to As implies greater ability for repair of membrane leakage.

Markovska et al. [54] reported that in Brassica juncea different enzymatic and non-enzymatic antioxidants had their maximum response to $\mathrm{Cd}$ induced oxygen stress at different levels of exposure. For example, with exposures of $0.0,10,30,50$ and $100 \mu \mathrm{M}$, ascorbate peroxidase activity was lowest at $30 \mu \mathrm{M}$ but highest at $50 \mu \mathrm{M}$ Cd. Anjum et al. [55] reported increasing enzymatic activity and decreasing non-enzymatic activity of antioxidants to increases in Cd induced oxidative stress in mungbean. Srivastava et al. [56] reported phytochelatin and antioxidant production responded differentially to As stress in Hydrillaverticillata. Production of superoxide dismutase, ascorbate peroxidase and glutathione reductase, enzymes used to neutralize free radicals, each peaked at different As exposure levels. Plants had a small growth increase at low As levels. Srivastava et al. [56] attributed a decrease in photosynthetic pigments to impaired uptake of $\mathrm{P}, \mathrm{Fe}, \mathrm{Cu}$ and $\mathrm{Mn}$.

Differences in the synchronization of mechanisms to adapt to low tissue $\mathrm{Cu}$ with mechanisms for As detoxification, such as, S metabolism for phytochelatan production may play a role in the growth response of iris. This may help explain the initial reduction in growth at low As exposure followed by the increase in growth at 
higher non-lethal exposure. Arsenic exposure causes widespread damage to a number of essential plant functions i.e. electron transport, neutralizing free radicals, photosynthesis, and membrane integrity [33] [34] [39]. Offsets in the timing of when factors controlling detoxification, damage control, and the initiation of secondary systems as primary systems are damaged may result in a complex growth response.

\section{Conclusion}

Arsenic toxicity can influence uptake of soil nutrients and their redistribution inside plant tissue. Calcium, Fe, $\mathrm{P}$ and $\mathrm{S}$ concentrations tended to increase as the plant attempted to detoxify or neutralize the effects of As. Reduction in $\mathrm{Cu}$ concentration is an early effect of As toxicity. Differences in mineral uptake reflect the plant's attempt to detoxify As (i.e. increase in S for S-containing As chelators), mitigate damage to the cell (i.e. Ca to repair leaky membranes) or continue cellular functions through alternative pathways (i.e. Fe superoxide dismutases to replace the function of $\mathrm{Cu} / \mathrm{ZnSOD}$ ).

\section{References}

[1] Woolson, E.A., Axley, J.H. and Kearney, P.C. (1971) Correlation between Available Soil Arsenic, Estimated by Six Methods, and Response of Corn (Zea mays L.). Soil Science Society of America Proceedings, 35, 101-105. http://dx.doi.org/10.2136/sssaj1971.03615995003500010030x

[2] Murphy, E.A. and Aucott, M. (1998) An Assessment of the Amounts of Arsenical Pesticides Used Historically in a Geographical Area. Science of the Total Environment, 218, 89-101. http://dx.doi.org/10.1016/S0048-9697(98)00180-6

[3] Zhao, F.J., Ma, J.F., Meharg, A.A. anf McGrath, S.P. (2009) Arsenic Uptake and Metabolism in Plants. New Phytologist, 181, 777-794. http://dx.doi.org/10.1111/j.1469-8137.2008.02716.X

[4] Cai, Y., Cabrera, J.C., Georgiadis, M. and Jayachandran, K. (2002) Assessment of Arsenic Mobility in the Soils of Some Golf Courses in South Florida. The Science of the Total Environment, 291, 123-134. http://dx.doi.org/10.1016/S0048-9697(01)01081-6

[5] Chirenje, T., Ma, L.Q., Szulczewski, M., Littell, R., Portier, K.M. and Zillioux, E. (2003) Arsenic Distribution in Florida Urban Soils: Comparison between Gainesville and Miami. Journal of Environmental Quality, 32, 109-119. http://dx.doi.org/10.2134/jeq2003.1090

[6] Marin, A.R., Masscheleyn, P.H. and Patrick, W.H. (1993) Soil Redox-pH Stability of Arsenic Species and Its Influence on Arsenic Uptake by Rice. Plant and Soil, 152, 245-253. http://dx.doi.org/10.1007/BF00029094

[7] Meharg, A.A. (1994) Integrated Tolerance Mechanisms: Constitutive and Adaptive Plant Responses to Elevated Metal Concentrations in the Environment. Plant, Cell and Environment, 17, 989-993. http://dx.doi.org/10.1111/j.1365-3040.1994.tb02032.x

[8] Kabata-Pendias, A. and Pendias, H., (1992) Trace Elements in Soils and Plants. CRC Press, Boca Raton.

[9] Meharg, A.A., Naylor, J. and Macnair, M.R. (1994) Phosphorus Nutrition of Arsenate-Tolerant and Nontolerant Phenotypes of Velvetgrass. Journal of Environmental Quality, 23, 234-238. http://dx.doi.org/10.2134/jeq1994.00472425002300020003x

[10] Asher, D.J. and Reay, P.F. (1979) Arsenic Uptake by Barley Seedlings. Australian Journal of Plant Physiology, 6, 495-466. http://dx.doi.org/10.1071/PP9790459

[11] Ullrich-Eberius, C.I., Sanz, A. and Novacky, A.J. (1989) Evaluation of Arsenate- and Vanadate-Associated Changes of Electrical Membrane Potential and Phosphate Transport in Lemna gibba $\mathrm{G}_{1}$. Journal of Experimental Botany, 40, 119-128. http://dx.doi.org/10.1093/jxb/40.1.119

[12] Bleeker, P.M., Schat, H., Vooijs, R., Verkleij, J.A.C. and Ernst, W.H.O. (2003) Mechanisms of Arsenate Tolerance in Cytisus striatus. New Phytologist, 157, 33-38. http://dx.doi.org/10.1046/j.1469-8137.2003.00542.x

[13] Meharg, A.A. and Jardine, L. (2003) Arsenite Transport into Paddy Rice (Oryza sativa) Roots. New Phytologist, 157, 39-44. http://dx.doi.org/10.1046/j.1469-8137.2003.00655.x

[14] Marin, A.R., Masscheleyn, P.H. and Patrick, W.H. (1992) The Influence of Chemical Form and Concentration of Arsenic on Rice Growth and Tissue Arsenic Concentration. Plant and Soil, 139, 175-183. http://dx.doi.org/10.1007/BF00009308

[15] Ma, J.F., Yamaji, N., Mitani, N., Xu, X.Y., Su, Y.H., McGrath, S.P. and Zhao, F.J. (2008) Transporters of Arsenite in Rice and Their Role in Arsenic Accumulation in Rice Grain. Proceedings of the National Academy of Sciences of the United States of America, 105, 9931-9935. http://dx.doi.org/10.1073/pnas.0802361105

[16] Mihucz, V.G., Tatar, E., Virag, I., Cseh, E., Fodor, F. and Zaray, G. (2005) Arsenic Speciation in Xylem Sap of Cucumber (Cucumis sativus L.). Analytical and Bioanalytical Chemistry, 383, 461-466. 
http://dx.doi.org/10.1007/s00216-005-3325-y

[17] Pickering, I.J., Prince, R.C., George, M.J., Smith, R.D., George, G.N. and Salt, D.E. (2000) Reduction and Coordination of Arsenic in Indian Mustard. Plant Physiology, 122, 1171-1177. http://dx.doi.org/10.1104/pp.122.4.1171

[18] Burló, F., Guijarro, I., Carbonell-Barrachina, A.A., Valero, D. and Martinez-Sánchez, F. (1999) Arsenic Species: Effects on and Accumulation by Tomato Plants. Journal of Agricultural and Food Chemistry, 47, 1247-1253. http://dx.doi.org/10.1021/jf9806560

[19] Carbonell-Barrachina, A.A., Aarabi, M.A., DeLaune, R.D., Gambrell, R.P. and Patrick, W.H. (1998) The Influence of Arsenic Chemical Form and Concentration on Spartina Patens and Spartina Alterniflora Growth and Tissue Arsenic Concentration. Plant and Soil, 198, 33-43. http://dx.doi.org/10.1023/A:1004285625998

[20] Caille, N., Zhao, F.J. and McGrath, S.P. (2005) Comparison of Root Absorption, Translocation and Tolerance of Arsenic in the Hyperaccumulator Pteris vittata and the Nonhyperaccumulator Pteris tremula. New Phytologist, 165, 755-761. http://dx.doi.org/10.1111/j.1469-8137.2004.01239.x

[21] Singh, N. and Ma, L.Q. (2006) Arsenic Speciation, and Arsenic and Phosphate Distribution in Arsenic Hyperaccumulator Pteris vittata L. and Non-Hyperaccumulator Pteris ensiformis L. Environmental Pollution, 141, 238-246. http://dx.doi.org/10.1016/j.envpol.2005.08.050

[22] Carbonell-Barrachina, A., Burló-Carbonell, F. and Mataix-Beneyto, J. (1994) Effect of Arsenite on the Concentrations of Micronutrients in Tomato Plants Grown in Hydroponic Culture. Journal of Plant Nutrition, 17, 1887-1903. http://dx.doi.org/10.1080/01904169409364853

[23] Sachs, R.M. and Michaels, J.L. (1971) Comparative Phytotoxicity among Four Arsenical Herbicides. Weed Science, 19, 558-564.

[24] Carbonell-Barrachina, A., Burló-Carbonell, F. and Mataix-Beneyto, J. (1995) Arsenic Uptake, Distribution and Accumulation in Tomato Plants: Effect of Arsenite on Plant Growth and Yield. Journal of Plant Nutrition, 18, 1237-1250. http://dx.doi.org/10.1080/01904169509364975

[25] Carbonell-Barrachina, A.A., Burló, F. and Mataix, J. (1998) Response of Bean Micronutrient Nutrition to Arsenic and Salinity. Journal of Plant Nutrition, 21, 1287-1299. http://dx.doi.org/10.1080/01904169809365482

[26] Brown, J.C., Clark, R.J. and Jones, W.E. (1977) Efficient and Inefficient Use of Phosphorous by Sorghum. Soil Science Society of America Journal, 41, 747-750. http://dx.doi.org/10.2136/sssaj1977.03615995004100040027x

[27] Lonergan, J.F. and Asher, C.J. (1967) Response of Plants to Phosphate Absorption and Its Relation to Growth. Soil Science, 103, 311-318. http://dx.doi.org/10.1097/00010694-196705000-00002

[28] Jacobs, L.W., Keeney, D.R. and Walsh, L.M. (1970) Arsenic Residue Toxicity to Vegetable Crops Grown on Plainfield Sand. Agronomy Journal, 62, 588-591. http://dx.doi.org/10.2134/agronj1970.00021962006200050011x

[29] Reed, S.T., Ayala-Silva, T., Dunn, C.B., Gordon, G.G. and Meerow, A. (2013) Screening Ornamentals for Their Potential as As Accumulator Plants. Journal of Agricultural Science, 5, 20-27. http://dx.doi.org/10.5539/jas.v5n10p20

[30] Moreno-Jiménez, E., Esteban, E., Fresno, T., López de Egea, C. and Peñalosa, J.M. (2010) Hydroponics as a Valid Tool to Assess Arsenic Availability in Mine Soils. Chemosphere, 79, 513-517. http://dx.doi.org/10.1016/j.chemosphere.2010.02.034

[31] SAS Institute (1999) SAS for Windows. SAS Inst., Cary, NC.

[32] Mengel, K. and Kirkby, E.A. (1987) Principals of Plant Nutrition. International Potash Institute, Worblaufen-Bern.

[33] Dehabadi, S.Z., Shoushtari, A. and Asrar, Z. (2013) Modulation of Arsenic Toxicity-Induced Oxidative Damage by Coronatine Pretreatment in Sweet Basil (Ocimum basilicum) Seedlings. Botany, 91, $442-448$. http://dx.doi.org/10.1139/cjb-2012-0296

[34] Mateos-Naranjo, E., Andrades-Moreno, L. and Redondo-Gómez, S. (2012) Tolerance to and Accumulation of Arsenic in the Cordgrass Spartina densiflora Brongn. Bioresource Technology, 104, 187-194. http://dx.doi.org/10.1016/j.biortech.2011.11.006

[35] Liu, Q., Hu, C., Tan, Q., Sun, X., Su, J. and Liang, Y. (2008) Effects of as on as Uptake, Speciation, and Nutrient Uptake by Winter Wheat (Triticum aestivum) under Hydroponic Conditions. Journal of Environmental Sciences, 20, 326-331. http://dx.doi.org/10.1016/S1001-0742(08)60051-0

[36] Melo, E.E.C., Costa, E.T.S., Guilherme, L.R.G., Faquin, V. and Nascimento, C.W.A. (2009) Accumulation of Arsenic and Nutrients by Castor Bean Plants Grown on an As-Enriched Nutrient Solution. Journal of Hazardous Materials, 168, 479-483. http://dx.doi.org/10.1016/j.jhazmat.2009.02.048

[37] Shaibur, M.R., Kitajima, N., Sugawara, R., Kondo, T., ImamulHuq, S.M. and Kawai, S. (2008) Physiological and Mineralogical Properties of Arsenic-Induced Chlorosis in Barley Seedlings Grown Hydroponically. Journal of Plant Nutrition, 31, 333-353. http://dx.doi.org/10.1080/01904160701854074 
[38] Baldwin, P.R. and Butcher, D.J. (2007) Phytoremediation of Arsenic by Two Hyperaccumulators in a Hydroponic Environment. Microchemical Journal, 85, 297-300. http://dx.doi.org/10.1016/j.microc.2006.07.005

[39] Singh, N., Ma, L.Q., Srivastava, M. and Rathinasabapathi, B. (2006) Metabolic Adaptations to Arsenic-Induced Oxidative Stress in Pterisvittata L and Pterisensiformis L. Plant Science, 170, 274-282. http://dx.doi.org/10.1016/j.plantsci.2005.08.013

[40] Meharg, A.A. and Hartley-Whitaker, J. (2002) Arsenic Uptake and Metabolism in Arsenic Resistant and Nonresistant Plant Species. New Phytologist, 154, 29-43. http://dx.doi.org/10.1046/j.1469-8137.2002.00363.x

[41] Cox, M.C. (1995) Arsenic Characterization in Soil and Arsenic Effects on Canola Growth. Ph.D. Thesis, Louisiana State University, Baton Rouge.

[42] Meharg, A.A. and Macnair, M.R. (1992) Suppression of the High-Affinity Phosphate-Uptake System: A Mechanism of Arsenate Tolerance in Holcus lanatus L. Journal of Experimental Botany, 43, 519-524. http://dx.doi.org/10.1093/jxb/43.4.519

[43] Reed, S., Ayala-Silva, T., Dunn, C.B., Gordon, G.G. and Meerow, A. (2013) Nutrient Uptake of Ornamental Plants Exposed to Arsenic in Hydroponic Solution. Journal of Agricultural Science, 5, 1-13. http://dx.doi.org/10.5539/jas.v5n12p1

[44] Cobbett, C.S. (2000) Phytochelatins and Their Roles in Heavy Metal Detoxification. Plant Physiology, 123, 825-832. http://dx.doi.org/10.1104/pp.123.3.825

[45] Mishra, S., Srivastava, S., Tripathi, R.D. and Trivedi, P.K. (2008) Thiol Metabolism and Antioxidant Systems Complement Each Other during Arsenate Detoxification in Ceratophyllum demersum L. Aquatic Toxicology, 86, $205-215$. http://dx.doi.org/10.1016/j.aquatox.2007.11.001

[46] Castillo-Michel, H.A., Zuverza-Mena, N., Parsons, J.G., Dokken, K.M., Duarte-Gardea, M., Peralta-Videa, J.R. and Gardea-Torresdey, J.L. (2009) Accumulation, Speciation, and Coordination of Arsenic in an Inbred Line and a Wild Type Cultivar of the Desert Plant Species Chilopsis linearis (Desert Willow). Phytochemistry, 70, 540-545. http://dx.doi.org/10.1016/j.phytochem.2009.01.010

[47] Rausch, T. and Wachter, A. (2005) Sulfur Metabolism: A Versatile Platform for Launching Defense Operations. Trends in Plant Science, 10, 503-509. http://dx.doi.org/10.1016/j.tplants.2005.08.006

[48] Benov, L. and Fridovich, I. (1996) Functional Significance of the Cu,ZnSOD in Escherichia coli. Archives of Biochemistry and Biophysics, 327, 249-253. http://dx.doi.org/10.1006/abbi.1996.0117

[49] Graham, R.D., Ascher, J.S., Ellis, P.A.E. and Shepherd, K.W. (1987) Transfer to Wheat of the Copper Efficiency Factor Carried on Rye Chromosome Arm 5RL. Plant and Soil, 99, 107-114. http://dx.doi.org/10.1007/BF02370158

[50] Finney, L.A. and O’Halloran, T.V. (2003) Transition Metal Speciation in the Cell: Insights from the Chemistry of Metal Ion Receptors. Science, 300, 931-936. http://dx.doi.org/10.1126/science.1085049

[51] CizewskiCulotta, V., Yang, M. and O’Halloran, T.V. (2006) Activation of Superoxide Dismutases: Putting the Metal to the Pedal. Biochimicaet Biophysica Acta, 1763, 747-758.

[52] Sheng, Y., Abreu, I.A., Cabelli, D.E., Maroney, M.J., Miller, A.F., Teixeira, M. and Valentine, S.J. (2014) Superoxide Dismutases and Superoxide Reductases. Chemical Reviews, 114, 3854-3918. http://dx.doi.org/10.1021/cr4005296

[53] Culotta, V.C., Klomp, L.W., Strain, J., Casareno, R.L., Krems, B. and Gitlin, J.D. (1997) The Copper Chaperone for Superoxide Dismutase. Journal of Biological Chemistry, 272, 23469-23472. http://dx.doi.org/10.1074/jbc.272.38.23469

[54] Markovska, Y.K., Gorinova, N.I., Nedkovska, M.P. and Miteva, K.M. (2009) Cadmium-Induced Oxidative Damage and Antioxidant Responses in Brassica juncea Plants. Biologia Plantarum, 53, 151-154. http://dx.doi.org/10.1007/s10535-009-0023-1

[55] Anjum, N.A., Umar, S., Ahmad, A. and Iqbal, M. (2008) Responses of Components of Antioxidant System in Moongbean Genotypes to Cadmium Stress. Communications in Soil Science and Plant Analysis, 39, 2469-2483. http://dx.doi.org/10.1080/00103620802292871

[56] Srivastava, S., Mishra, S., Tripathi, R.D., Dwivedi, S., Trivedi, P.K. and Tandon, P.K. (2007) Phytochelatins and Antioxidant Systems Respond Differentially during Arsenite and Arsenate Stress in Hydrilla verticillata (L.f.) Royle. Environmental Science and Technology, 41, 2930-2936. http://dx.doi.org/10.1021/es062167j 